\title{
Orientation Selectivity of Synaptic Potentials in Neurons of Cat Primary Visual Cortex
}

\author{
David Ferster \\ Department of Neurobiology and Physiology, Northwestern University, Evanston, llinois 60201
}

\begin{abstract}
Neurons of the visual cortex of the cat were penetrated with intracellular electrodes and postsynaptic potentials evoked by visual stimuli recorded. By alternately polarizing the cell with steady current injected through the recording electrode, IPSPs and EPSPs could be recorded and analyzed independently. $\mathrm{Hy}$ perpolarizing current suppressed IPSPs and enhanced EPSPs by moving the membrane potential toward the IPSP equilibrium potential. Depolarizing the cell toward the EPSP equilibrium potential enhanced IPSP. The responses to electrical stimulation of the LGN, where EPSPs and IPSPs could be distinguished easily by virtue of their characteristic latencies and shapes, were used to set the current injection to the appropriate level to view the two types of synaptic potential.

EPSPs were found to be well oriented in that maximal depolarizing responses could be evoked at only one stimulus orientation; rotating the stimulus orientation in either direction produced a fall in the EPSP response. IPSPs were also well tuned to orientation, and invariably the preferred orientations of FPSPs and IPSPs in any one cell were identical. In addition, no systematic difference in the width of tuning of the two types of potential was seen. This result has been obtained from penetrations of over 30 cortical cells, including those with simple and complex receptive fields. It is concluded that orientation of cortical receptive fields is neither created nor sharpened by inhibition between neurons with different orientation preference. The function of inhibition evoked simultaneously with excitation by optimally oriented stimuli has yet to be determined, though it is likely to be the mechanism underlying other cortical receptive field properties, such as direction selectivity and endstopping.
\end{abstract}

The description of receptive field properties occupies a middle level in our attempt to understand sensory systems. One important task is to relate these properties to the perceptual abilities of the entire organism. A second is to explain receptive field properties in terms of underlying synaptic mechanisms. In the visual cortex, this second question has drawn particular attention because the receptive field properties of cortical neurons arc so radically different from those of its major visual input, the principal cells of the LGN. End-stopping, direction selectivity, retinal disparity sensitivity, and orientation selectivity all appear for the first time in the visual cortex, all created by the specific organization of the connections between the LGN and cortex and within the cortex itself.

Much is known about the connections underlying cortical receptive fields, from anatomical studies of the projections within the visual system, and by inference from detailed studies of

Received June 10, 1985; revised Sept. 27, 1985; accepted Oct. 30, 1985.

This work was supported by Grant R01 EY04726 from the National Institutes of Health and by the Searle Foundation. I wish to thank Dr. Eric Frank for invaluable discussions and Dr. John Robson for his comments on the manuscript. Correspondence should be addressed to Dr. Ferster at the above address.

Copyright (c) 1986 Society for Neuroscience $0270-6474 / 86 / 051284-18 \$ 02.00 / 0$ the receptive fields themselves. It is the interaction of excitatory and inhibitory synaptic events on the membrane of each neuron, however, that ultimately determines when the neuron will fire and when not; a description of these inputs, their origins, and visual responses should contribute substantially to an explanation of cellular receptive field properties. In a previous series of experiments, Ferster and Lindström (1983, 1985a, 1985b) traced some of the major geniculocortical and intracortical connections by recording synaptic potentials evoked from different parts of the visual pathways. In the present experiments, the behavior of these connections has been examined under more physiological conditions. By recording the responses of EPSPs and IPSPs to visual stimulation, their contribution to neuronal behavior could be studied directly.

Perhaps the quintessential cortical receptive field property is orientation selectivity: Nowhere else in the retinocortical pathway are so many neurons so sensitive to orientation. Hubel and Wiesel (1962), when first describing the property, proposed the serial processing model as a mechanism for the production of orientation selectivity: from the spatial relationship of receptive fields of the geniculate neurons providing excitatory drive to simple cells. A second hypothesis attributes the property to intracortical inhibitory interactions. In the cross-orientation inhibition model, neurons with different orientation preference inhibit each other, preventing responses to inappropriately oriented stimuli (Blakemore and Tobin, 1972; Morrone et al., 1982; Sillito et al., 1980). Implicit to the model is the assumption that the excitatory drive is poorly tuned in orientation and would by itself result in inappropriate responses that the inhibition is assigned to prevent. The experiments described in this paper were designed to examine the origin of orientation selectivity directly by determining the orientation tuning of both excitatory and inhibitory synaptic inputs to cortical neurons.

\section{Materials and Methods}

\section{Animal preparation}

Recordings were made from anesthetized paralyzed cats weighing 2-3 $\mathrm{kg}$. Anesthesia was induced with ketamine $\mathrm{HCl}(25 \mathrm{mg} / \mathrm{kg}$, i.m.) followed by sodium pentothal $(20-30 \mathrm{mg} / \mathrm{kg}$, i.v.) and maintained with small additional doses of pentothal $(1-2 \mathrm{mg} / \mathrm{kg} / \mathrm{hr})$. The ECG was monitored and additional anesthetic administered if the heart rate changed in response to painful stimuli. A paralytic was infused (gallamine triethiodide, $15 \mathrm{mg} / \mathrm{kg} / \mathrm{hr}$, i.v.) and artificial respiration adjusted to maintain end-expiratory $\mathrm{CO}_{2}$ at $4 \%$. Movements of the brain associated with respiration were minimized by suspending the animals from a clamp on the midthoracic vertebrae and by performing a bilateral pneumothorax. Temperature was maintained at $38.5^{\circ} \mathrm{C}$.

\section{Recording}

Glass micropipettes of 50-100 $\mathrm{M} \Omega$ resistance, filled with $2 \mathrm{~m}$ potassium methylsulfate or $3 \mathrm{M}$ potassium acetate, were driven though the cortex with a stepping-motor microdrive (Transvertex AB, Sweden). After placing the tip of the electrode at the surface of the brain in preparation for advancing it into the cortex, the exposed cortex was covered with a solution of warm agar ( $3 \%$ in $0.9 \%$ saline). Potentials were stored on 
an FM tape recorder, along with signals representing the position and orientation of the visual stimulus, and the amount of current injected through the recording electrode (see below). A "virtual DC" circuit was used to offset the DC level of recorded potentials to $0 \mathrm{mV}$ at the beginning of each electrical stimulus or of each sweep or flash of the visual stimulus. In this way, potentials could be recorded at high gain despite large $D C$ changes caused by passing current through the electrode, particularly when the bridge circuit of the microelectrode amplifier was not perfectly balanced. Records of visually evoked potentials were made from the tape by playing the tape onto a strip chart recorder. The tape was run at slow speed to allow the recorder to capture higher-frequency components of the response, up to $1000 \mathrm{~Hz}$. To make the high-sweepspeed records of electrically evoked potentials (Figs. 4, $C$ and $D$, and $6, B$ and $D$, for example) with all the high-frequency components preserved, the taped potentials were digitized and displayed on an oscilloscope or plotted on a dot matrix printer.

\section{Separation of EPSPS and IPSPS}

Both at rest (when no visual stimulus was presented) and during the presentation of a visual stimulus, the records' taken from most cells consisted of numerous synaptic potentials, often overlapping each other in time (Creutzfeldt et al., 1974; Innocente and Fiore, 1974). It was extremely difficult to extract useful information from such records, the beginnings of EPSPs often being indistinguishable from the ends of IPSPs, all of which are superimposed on action potentials and a substantial level of noise. The solution to the problem is to polarize the cell with DC current injected through the recording electrode; negative current suppresses IPSPs and enhances EPSPs by polarizing the cell toward the IPSP equilibrium potential. Alternatively, positive current suppresses EPSPs and enhances IPSPs by bringing the cell's potential away from the IPSP equilibrium potential and toward that of the EPSPs. In either case, action potentials are suppressed as well, either by keeping the cell below threshold (hyperpolarization) or by inactivating the spike mechanism (depolarization). But it was difficult to gauge the effect of the current and adjust it to the appropriate level by examining the spontaneous or visually evoked synaptic activity. It was too difficult to determine which of the almost random barrage of potentials was an EPSP, which an IPSP reversed by too much negative current, which an aborted action potential, and so on.

Instead, the appropriate level of current injection was determined by examining the intracellular response to electrical stimulation in the LGN. Electrically evoked EPSPs and IPSPs are large and reproducible and easily distinguished by their characteristic latencies and shapes. While examining them, it is a simple matter to adjust the current level to record almost exclusively one or the other type of synaptic potential. Figures $6, C$ and $D$, for example, show monosynaptic EPSPs evoked from the LGN with no current injected, and disynaptic IPSPs visible with almost no contamination by EPSPs when $0.7 \mathrm{nA}$ of negative current was injected through the recording electrode. The presence of a stimulating electrode in the LGN was an indispensible tool for the reliable separation of the two types of synaptic potential.

One further consequence of the use of current to polarize the cell is that the absolute size of recorded potentials may not reflect their size under normal conditions. It is instcad strongly dependent on the current level and the quality of the intracellular penetration. What is of interest here, however, is not so much the absolute size of the responses, but the change in the visually evoked responses as a function of stimulus orientation. As long as the current is kept constant and the state of the penetration does not change, comparison of the response to different stimuli should reflect the basic receptive field properties of the intracellularly recorded potentials.

Spurious changes in the response to visual stimulation could also be caused by improvement or deterioration in the quality of the penetration from trial to trial. Two indicators were used to insure that cells in which such a change occurred were not included in the data. The first consisted of the response to electrical stimulation; any change in the state of the cell was reflected in the amplitude of electrically evoked potentials at a given level of current injection. In addition, stimulus conditions were alternated as much as possible. A stimulus at the optimal orientation was presented for three to five sweeps, followed by as many stimuli at other orientations. If, when the stimulus was turned back to the optimal orientation, the response did not return to the same magnitude as first observed, the intervening data were discarded. This sequence was repeated at different levels of current injection as long as the penetration remained stable.
There was at first some possibility that visually evoked potentials were made up of two components, a real transmembrane potential and an extracellular field potential on which it was superimposed. No extracellular field potential generated by visual stimuli was ever detected, and so extracellular records are not illustrated.

The resting potential of recorded cells was monitored in most experiments, though it was used less as a criterion for judging the quality of the penetrations than the responses to visual and electrical stimulation themselves. During the best penetrations (1) action potentials were present, either with no current injected from the electrode or with a small hyperpolarizing current; (2) responses to electrical stimulation without current injection consisted primarily of EPSPs; (3) adequate visual stimulation resulted in visible depolarization; (4) a few nanoamps of depolarizing current, at most, were required to suppress EPSPs and enhance IPSPs. When measured, the resting potential associated with these criteria was greater than $45-50 \mathrm{mV}$. Such penetrations could last for more than $50 \mathrm{~min}$. The input resistance of the cells could not be measured reliably with current pulses: With high-resistance electrodes having several millimeters near the tip embedded in agar, the electrode time constant was too long compared to that of the cell itself.

With resting potentials slightly less than $45 \mathrm{mV}$, action potentials were not visible, nor could they be restored in more than an attenuated form by hyperpolarizing current. Without current, only IPSPs were visible, though a few nanoamps of hyperpolarizing current could bring out visible EPSPs. The behavior of synaptic potentials of these penetrations was no different from those described above. In fact, in those cases where the best penetrations deteriorated after having been studied for some time, the only visible change in response was that the EPSPs required more current to visualize, and their amplitudes became smallcr. Their receptive fields did not change. Resting potentials of $35 \mathrm{mV}$ and less were accompanied only by IPSPs in response to visual or electrical stimulation, and even $5 \mathrm{nA}$ of current or more was insufficient to render EPSPs visible. No data were taken from these cells. It should be mentioned that no cells reported in this study were studied extracellularly. Though it would be desirable to compare extracellularly recorded receptive fields with those of EPSPs and IPSPs, this was rarely possible with the high-resistance electrodes used.

\section{The laminar position of recorded cells}

The stimulating electrode in the LGN was also important for determining the laminar position of recorded cells. Dyes for marking electrode position extracellularly or HRP solutions for intracellular staining both increase the resistance and reduce the current-passing capabilities of electrodes, making physiological studies more difficult. Neither were used in these experiments. Ferster and Lindström (1983) have found, however, that cortical potentials recorded in response to electrical stimulation in the retinotopically corresponding region of the LGN change dramatically from layer to layer and can be used to determine the laminar position of recorded cells. Briefly, layer 2 cells are characterized by di- or trisynaptic EPSPs and IPSPs. Layer 3 cells always exhibit a monosynaptic EPSP and disynaptic IPSP, which are often accompanied by a disynaptic EPSP as well. Layer 4 cells also show a monosynaptic EPSP and disynaptic IPSP sequence, but they differ from other cortical cells in that they receive direct excitation from collaterals of layer 6 corticogeniculate neurons. The antidromic activation of these latter cells results in a long-latency $(3-4 \mathrm{msec})$, slowly rising potential that grows dramatically with increasing stimulus frequency (Ferster and Lindström, 1985b). Entering layers 5 and 6 is signaled by the appearance of cells antidromically activated from the LGN at short $(<3 \mathrm{msec})$ and long $(>3 \mathrm{msec})$ latency. The former are invariably excited di- or trisynaptically and the latter monosynaptically from the LGN. In combination with the depth of the electrode and with the observed receptive field properties, these potentials serve to identify cortical neurons with great reliability (see Ferster and Lindström, 1983).

\section{Electrical stimulation}

Electrical stimuli consisted of cathodal current pulses $200 \mu \mathrm{sec}$ long and of up to $1500 \mu \mathrm{A}$ amplitude applied to the LGN through a lacquercoated tungsten electrode. The electrode was first placed stereotaxically in the LGN and its position then adjusted so that cells recorded at its tip had receptive fields within $2^{\circ}-4^{\circ}$ of the area centralis, to match the receptive field positions of recorded cortical cells. Once the appropriate region of the LGN was found, the electrode tip was withdrawn to just above the upper border of lamina A. Stimuli for all illustrated traces were delivered at a frequency of $2 / \mathrm{sec}$. 

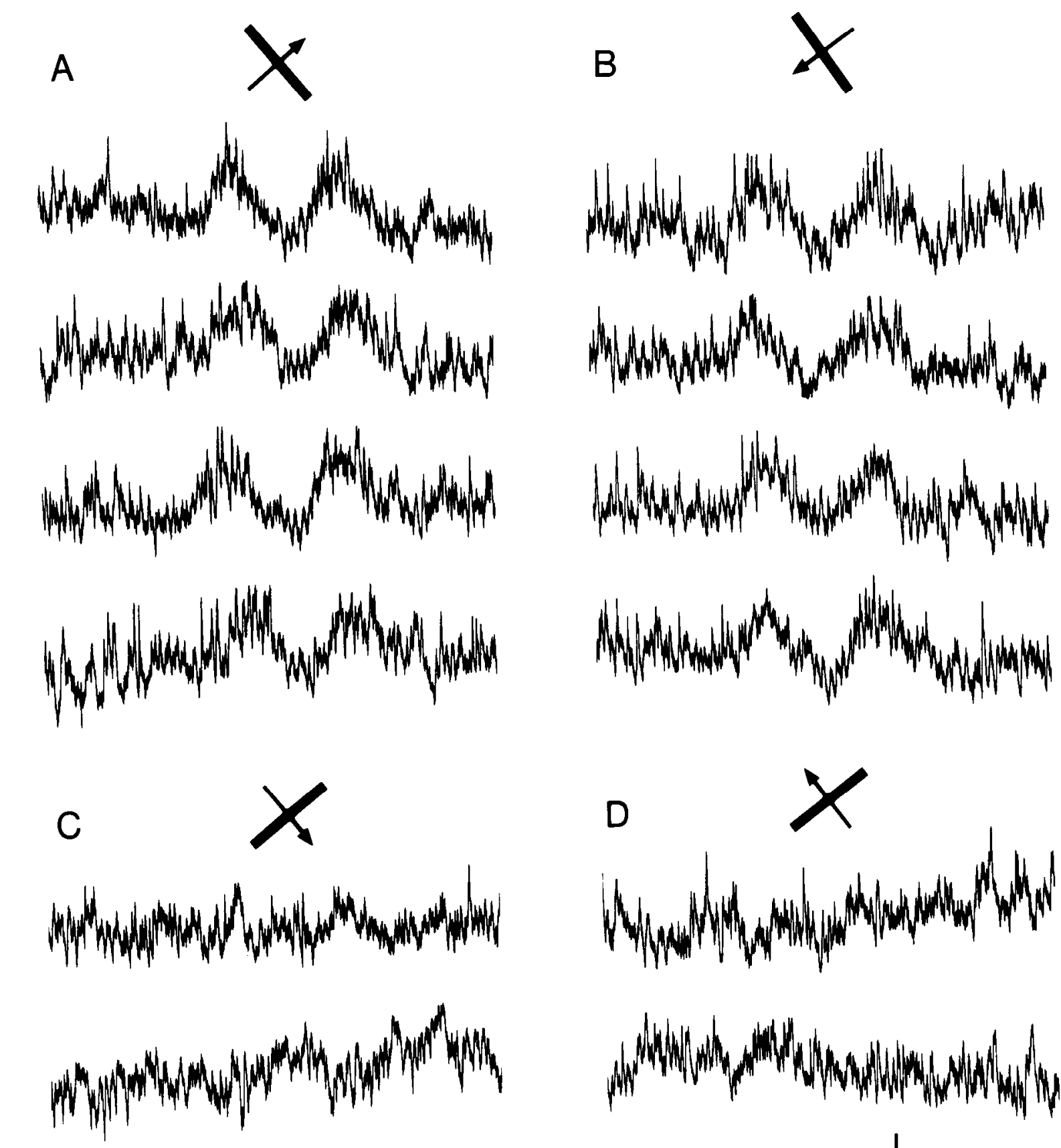

$-\ln A$
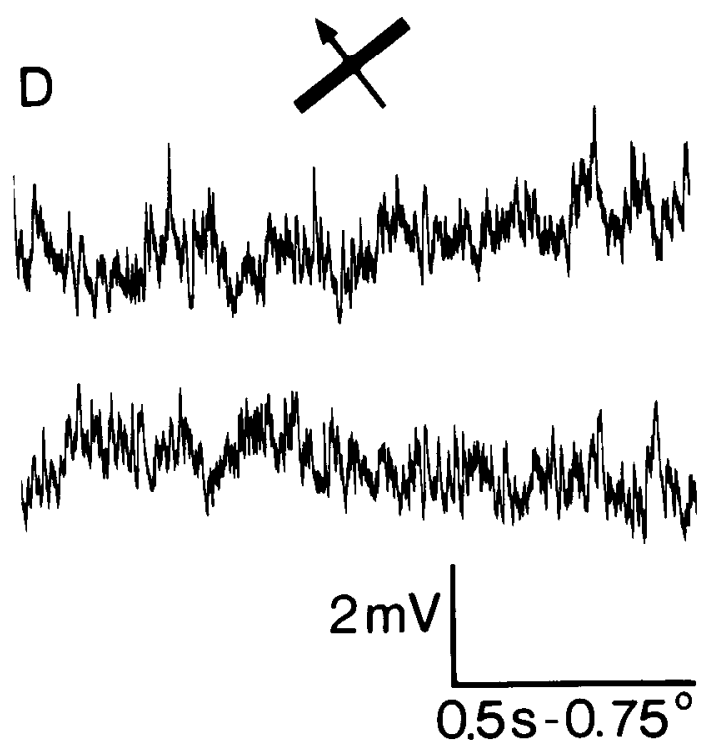

Figure 1. EPSPs recorded from a simple cell in layer 4 of area 17. Each trace represents the response to a bar of light swept across the receptive field with constant velocity $(1.5 \% \mathrm{sec})$. The diagram above each set of traces represents the orientation and direction of motion of the stimulus. $A$ and $B$, Preferred orientation; $C$ and $D$, null orientation. Several traces for each stimulus condition are presented to indicate the reproducibility of the responses. In this and other figures of synaptic potentials, the current injected into the cell through the recording electrode is indicated at lower left. In this case, the cell was hyperpolarized by $1 \mathrm{nA}$ of current. The calibration mark for the horizontal axis gives both time (sec) and the corresponding travel of the stimulus (deg).

\section{Visual stimulation}

Accommodation was paralyzed with atropine and the nictitating membranes retracted with Neosynephrine. Each eye was fitted with a contact lens of sufficient curvature to focus it on a tangent screen 57 inches away. The background luminance of the screen was 10 candellas $/ \mathrm{m}^{2}$. The outer peripheral portion of each lens was blackened to form a 4 $\mathrm{mm}$ artificial pupil. Focus was determined by projecting an image of the retina on the screen with an ophthalmoscope.
After a cell was penetrated, the receptive field properties of its synaptic potentials were studied with stimuli projected onto the tangent screen with a hand-held projector. When the approximate position, ocular dominance, and orientation preference of the receptive field were established, a mechanically controlled stimulus was used to sweep bars of light repeatedly across the receptive field with constant velocity at different orientations. Alternatively, a bar could be flashed repeatedly at any position and orientation on the screen. The luminance of all stimuli was 40 candellas $/ \mathrm{m}^{2}$. Signals proportional to the instantaneous 

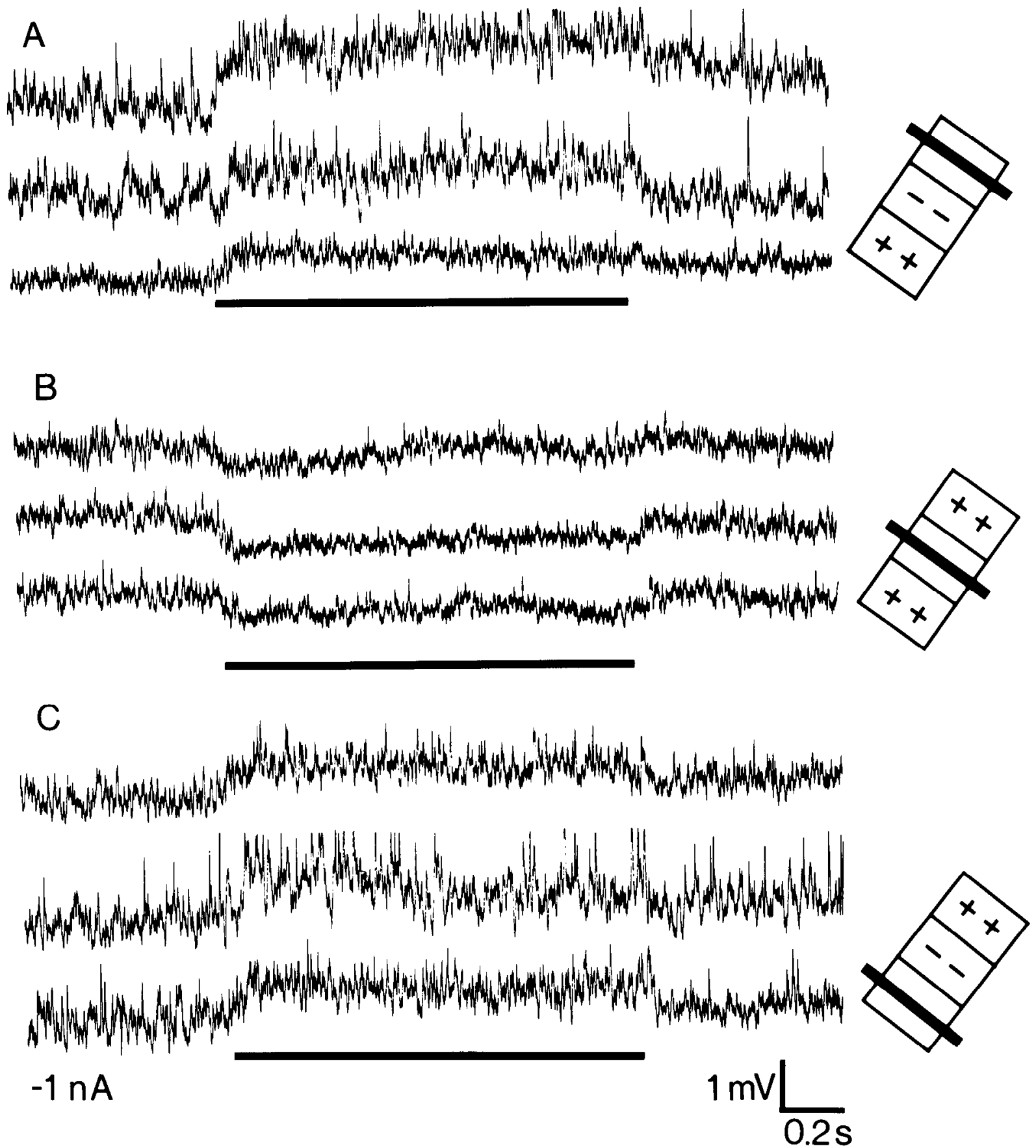

Figure 2. EPSPs recorded from the same simple cell as in Figure 1. Each trace represents the response to a bar of light flashed in one of the subregions of the receptive field. The position of the stimulus within the receptive field is indicated to the right of each set of traces. $A$ and $C$, The bar fell on one of two ON regions of the receptive field. $B$. The bar fell on the OFF region. The horizontal lines beneath each set of traces indicate the time during which the bar was on.

position and orientation were recorded on two different channels of the FM tape recorder along with the responses they evoked from the cell being recorded.

\section{Results}

Receptive field properties of synaptic potentials in simple cells

The subregions of simple cell receptive fields are thought to arise from synaptic excitation by geniculate principal cells of the corresponding center type: ON-center cells forming ON regions, OFF-center cells forming OFF regions. It was no surprise, therefore, that the receptive fields of simple cells obtained from plotting the visual responses of intracellularly recorded EPSPs exhibit subfields in the same way that extracellularly plotted receptive fields do. The records in Figures 1-4 were taken from a layer 4 simple cell with three subregions in its receptive field, which was located approximately $3^{\circ}$ from the area centralis.

Figures 1 and 2 show the responses of EPSPs to visual stimulation, either flashing or sweeping a bar of light in the receptive field. Before considering the response to visual stimulation in detail, however, it must be established that the level of current injection used was appropriate for revealing EPSPs. Note that the DC current injected through the electrode in Figures 1 and 
2 was $-1 \mathrm{nA}$. (The injected current is indicated to the lower left of these and all subsequent figures.) As described in Materials and Methods, the response to electrical stimulation in the LGN was used to set the current for recording EPSPs or IPSPs. From Figure $4 C$, it can be seen that the steady hyperpolarization produced by $-1 \mathrm{nA}$ almost totally suppressed IPSPs as the membrane potential was brought closer to the IPSP equilibrium potential. Only EPSPs remain visible. The first component in the EPSP response follows the stimulus artifact by $1.7 \mathrm{msec}$. The second response at $3.6 \mathrm{msec}$ reflects the antidromic activation of layer 6 corticogeniculate cells and their collaterals projecting into layer 4 . The size of this potential was very sensitive to stimulus frequency, increasing dramatically at $15 \mathrm{~Hz}$ (see Ferster and Lindstrom, 1985b). Its presence served to confirm the location of the cell as layer 4 .

Figure 1 contains records taken with the cell hyperpolarized to reveal EPSPs while a bar of light was swept across the receptive field at the optimal orientation $(A, B)$ and at $90^{\circ}$ to the optimal $(C, D)$. There are four stimulus conditions, two directions of motion at two different orientations, as indicated by the diagrams above each set of traces. Several records are displayed for each stimulus condition to indicate the consistency of the response. The two waves of depolarization evident in the upper records reflect the presence of the three subfields, a central OFF region flanked by two ON regions of about equal size and strength. Note that the depolarizations last several hundred milliseconds, many times the duration of EPSPs evoked electrically from the LGN, which typically last less than $10 \mathrm{msec}$ (Fig. 4C). Thus, the visually evoked response must be made up of many individual potentials, each of which must be small compared to the noise level of the traces.

The repolarization of the cell that takes place as the bar passes across the OFF region in some cases actually brings the potential slightly below the resting level (taken to be the potential observed when the stimulus is far from the receptive field). If, in fact, the central OFF region is mediated by excitation from OFFcenter geniculate neurons, this hyperpolarization could be explained most simply by the reduction of background activity in the presynaptic OFF-center cells as the bar encounters their receptive field centers. In other words, the hyperpolarization would he the result of the withdrawal of tonic excitation, not of an increase in inhibition.

Figure 2 contains records of responses evoked by flashing a bar in the three subfields of the same simple cell as in Figure 1. The same level of current was injected to reveal EPSPs, and here again several records are shown for each stimulus condition. The diagrams to the right illustrate the position of the bar within the receptive field. The line beneath each set of traces indicates the time during which the stimulus was on. As expected, flashing the bar in either $\mathrm{ON}$ region $(A, C)$ produced a depolarization at the onset and a repolarization at the offset. Conversely, flashing the stimulus in the OFF region resulted in a hyperpolarization at the onset and repolarization at the offset. Once again, this is most likely a withdrawal of cxcitation, not true inhibition, since IPSPs at this level of current injection produce no apparent hyperpolarization of their own (Fig. 4C).

Although the receptive fields of the geniculate relay cells thought to be responsible for the subfields of simple cells are radially symmetric and have little orientation selectivity, the EPSPs recorded in simple cells are highly orientation selective, as are simple cells themselves. In Figure 1, $C$ and $D$, are shown the responses to sweeping a bar across the receptive field at $90^{\circ}$ to the optimal orientation. As can be seen, no consistent response is visible. Estimating roughly, given the size of the responses in $A$ and $B$ and the amplitude of the noise in the traces, it would seem that any response to the improperly oriented stimulus is at least 10 -fold smaller than that to the optimal stimulus.
It could be argued that some EPSPs may be evoked by a stimulus at $90^{\circ}$ to the optimal, but that they disappear only because they are masked by inhibition. This seems unlikely for two reasons. First, at the level of current injection used, IPSPs are not effective: They produce no hyperpolarization of the cell, and more importantly, they have little apparent shunting effect on the EPSPs. At least in the electrically evoked responses of Figure $4 C$, there is no attenuation of the EPSPs associated with the onset of the IPSPs at $2.5 \mathrm{msec}$. Second, no IPSPs can be recorded at the null orientation even with the cell depolarized (see below). It may still be that the excitation from the LGN might be suppressed by presynaptic inhibition, a possibility more difficult to exclude with the current methods, but the lack of appropriate anatomical evidence for cortical presynaptic inhibition makes it unlikely.

As alluded to above, few IPSPs were evoked by a stimulus oriented $90^{\circ}$ from the optimal. Surprisingly, IPSPs had the same orientation preference as the EPSPs in every cell examined. IPSPs could be recorded from the simple cell of Figures 1 and 2 merely by changing the amount of current being injected through the electrode (Fig. 3). The exact change in the cell's potential caused by the current was not determined, since polarization of the electrode makes such measurements unreliable even with the amplifier's bridge in balance. Nevertheless, the effect of the current on synaptic potentials could be judged easily from the responses to electrical stimulation of the LGN. By comparing Figure $4, C$ and $D$, it is clear that $2 \mathrm{nA}$ of positive current depolarized the cell to a level at which the monosynaptic EPSPs all but disappeared, while the disynaptic IPSPs were greatly enhanced. Figure 3 contains the responses to visual stimulation recorded with this new current level. Note that the stimulus conditions are the same as in Figure 1: A bar of the same length and width was swept over the receptive field at the same velocity, beginning at the same position. The only difference between the two figures is in the amount of current that was injected while they were recorded.

The receptive field organization revealed by the IPSP records is much different from that of the EPSPs. A single wave of hyperpolarization is present, its center coincident with the center of the EPSP field. The size of the field is similar to that of the EPSPs, though the strongest inhibition is superimposed on the OFF region seen in the EPSP records of Figure 1. The hyperpolarization is accompanied by a definite increase in the noisiness of the trace. On closer inspection, it can be seen that the slow hyperpolarization is associated with a barrage of unitary events, each one presumably the result of a single spike in a presynaptic cell (see below). These fast potentials (10 $\mathrm{msec}$ duration) can be heard easily on the audio monitor (unlike the EPSPs) as a rapid fluttering sound, making it a simple matter to determine their receptive field properties quickly by ear, much as one can from extracellularly recorded spikes. Here again, the response is very consistent from trace to trace. The relative lack of unitary events seen while the stimulus is outside the receptive field is consistent with the low spontaneous activity of cortical neurons compared to that of geniculate principal cells: Given the disynaptic connectivity of the IPSPs visible in Figure $4 C$, they are likely to be mediated by a cortical interneuron-presumably also in layer 4 (see Ferster and Lindström, 1983).

The stimulus orientation used in Figure $3, A$ and $B$, for comparison with EPSP responses was chosen to match the corresponding parts of Figure 1; that is, the bar was swept in the optimal orientation for evoking EPSPs. Certainly the stimulus is also effective for evoking IPSPs as well, but to answer the question raised in the introduction, the best orientation for the IPSPs must be found independently. From Figure 3, $C$ and $D$, it is clear that a stimulus $90^{\circ}$ away from the one used in Figure $3, A$ and $B$, is as poor a stimulus for the IPSPs as it is for the EPSPs. No consistent IPSP response is visible. If any response 

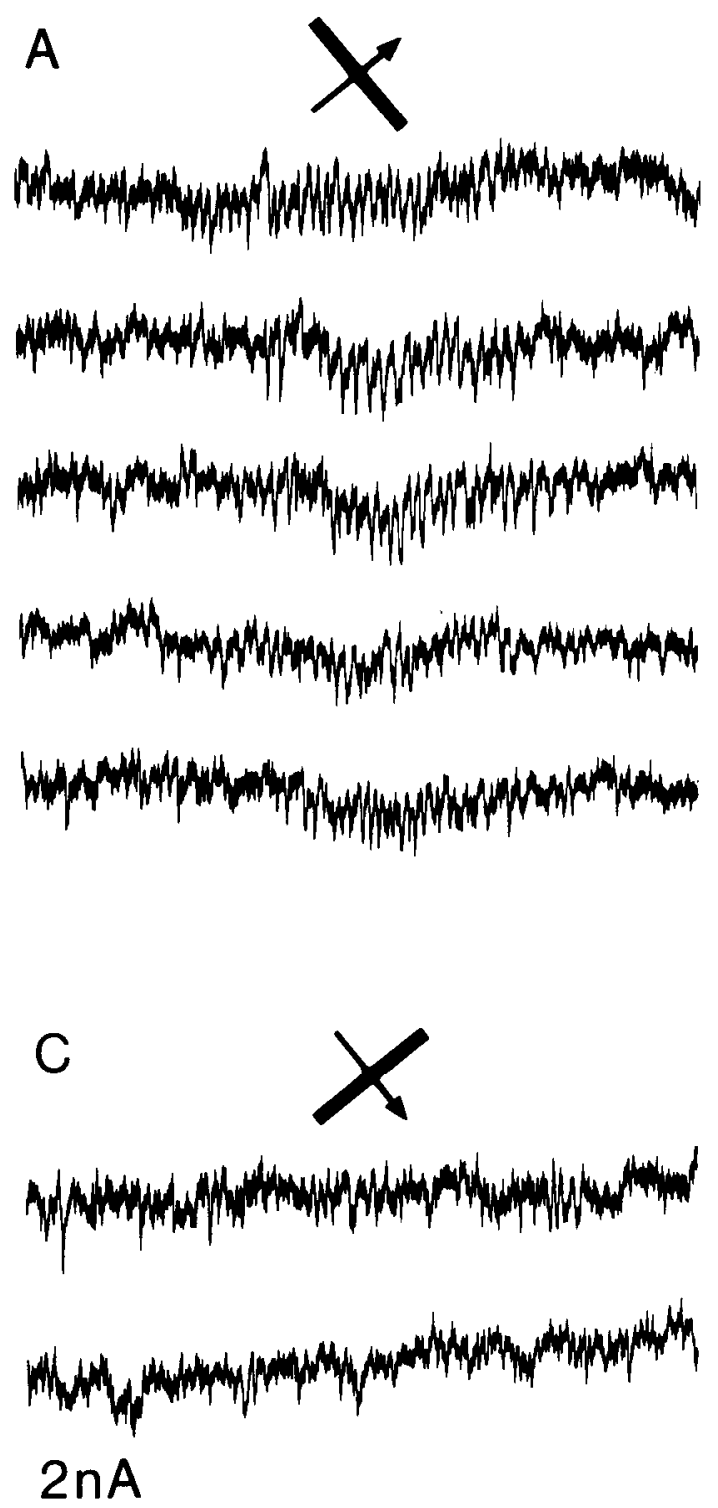
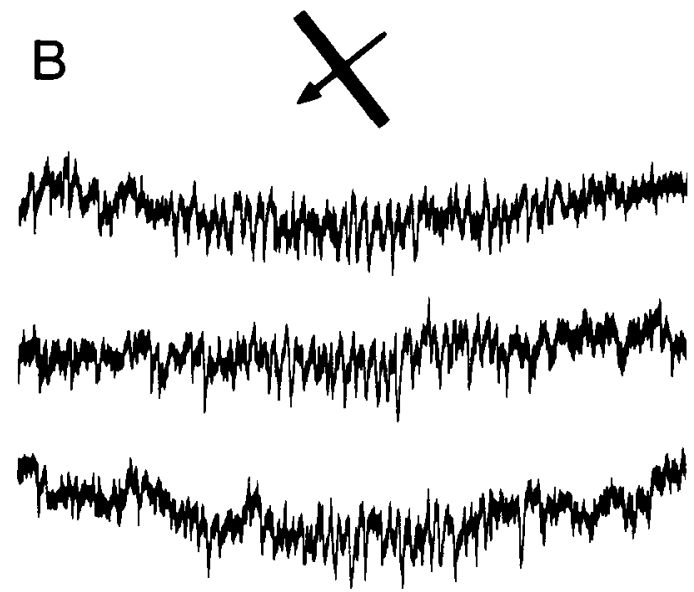

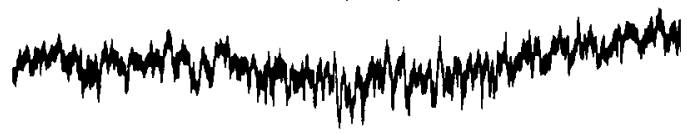
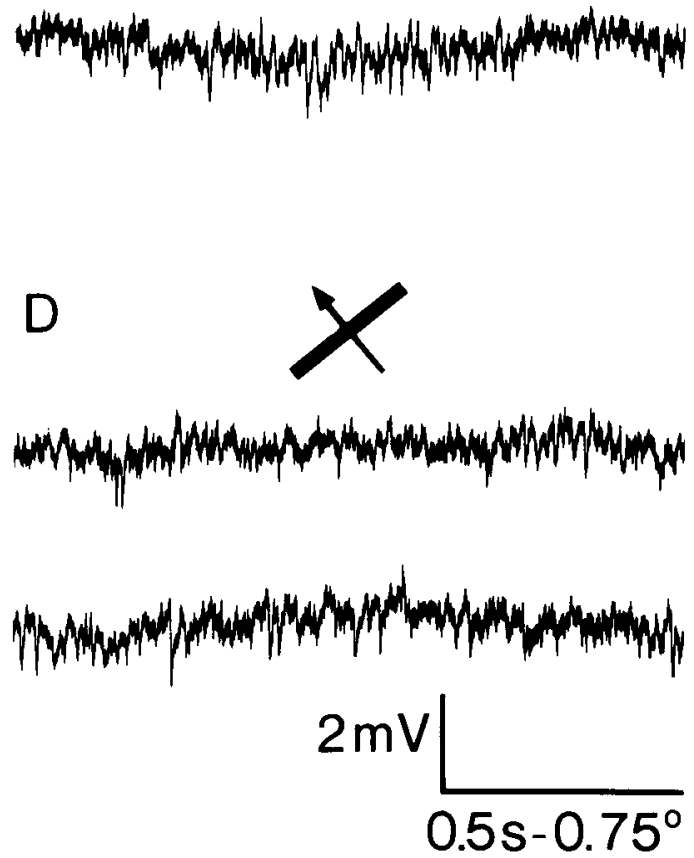

Figure 3. IPSPs recorded from the same simple cell as in Figures 1 and 2. Each trace represents the response to a bar of light swept across the receptive field with constant velocity $(1.5 \% \mathrm{sec})$. Stimulus starting position, size, and velocity are identical to those used in Figure 1 . The diagram above each set of traces represents the orientation and direction of motion. $A$ and $B$, Preferred orientation; $C$ and $D$, null orientation. The current injected through the electrode has now been reversed to $2 \mathrm{nA}$ of depolarizing current to reveal IPSPs.

is present at all, it too must be at least $10 \times$ smaller than the response in $A$ and $B$.

Figure 4 contains evidence that, in fact, the EPSP and IPSP responses are maximal at the same orientation. The largest response in each case is obtained at about $45^{\circ}$ clockwise from horizontal; turning the stimulus results in a gradual reduction in the response with each step away from the optimal. There is some variability from trace to trace at each orientation (not shown), but the records illustrated are not atypical. There is little doubt that the widths of orientation tuning for the two types of synaptic potential are comparable; if anything, the EPSPs are more broadly tuned than the IPSPs. What is most significant, however, is that the optimal orientations for the two are identical; the same stimulus evokes maximal excitation and inhibition, though at different times during the stimulus sweep. The same pattern of response has been obtained in all eight simple cells in which EPSPs and IPSPs could be studied at different orientations.

A second simple cell is illustrated in Figures 5 and 6. The receptive field of this cell is identical in structure to that of the cell in Figures 1-4: The EPSP receptive field is made up of a single OFF region flanked by two ON regions (Fig. 5, top left). The receptive field is slightly bigger, however, reflecting its greater eccentricity. The response to only one direction of stimulus motion is shown in Figure 1. The response to the other direction of motion was identical in shape, though slightly smaller. Once again, the EPSP response disappeared when the slit was turned $90^{\circ}$ (Fig. 5, top right), with intermediate orientations giving intermediate responses (not shown). The current used to obtain the EPSP records was $0 \mathrm{nA}$ since the resting potential of this cell was greater than $50 \mathrm{mV}$, sufficient to allow direct recording of EPSPs without current, as indicated by the response to stim- 


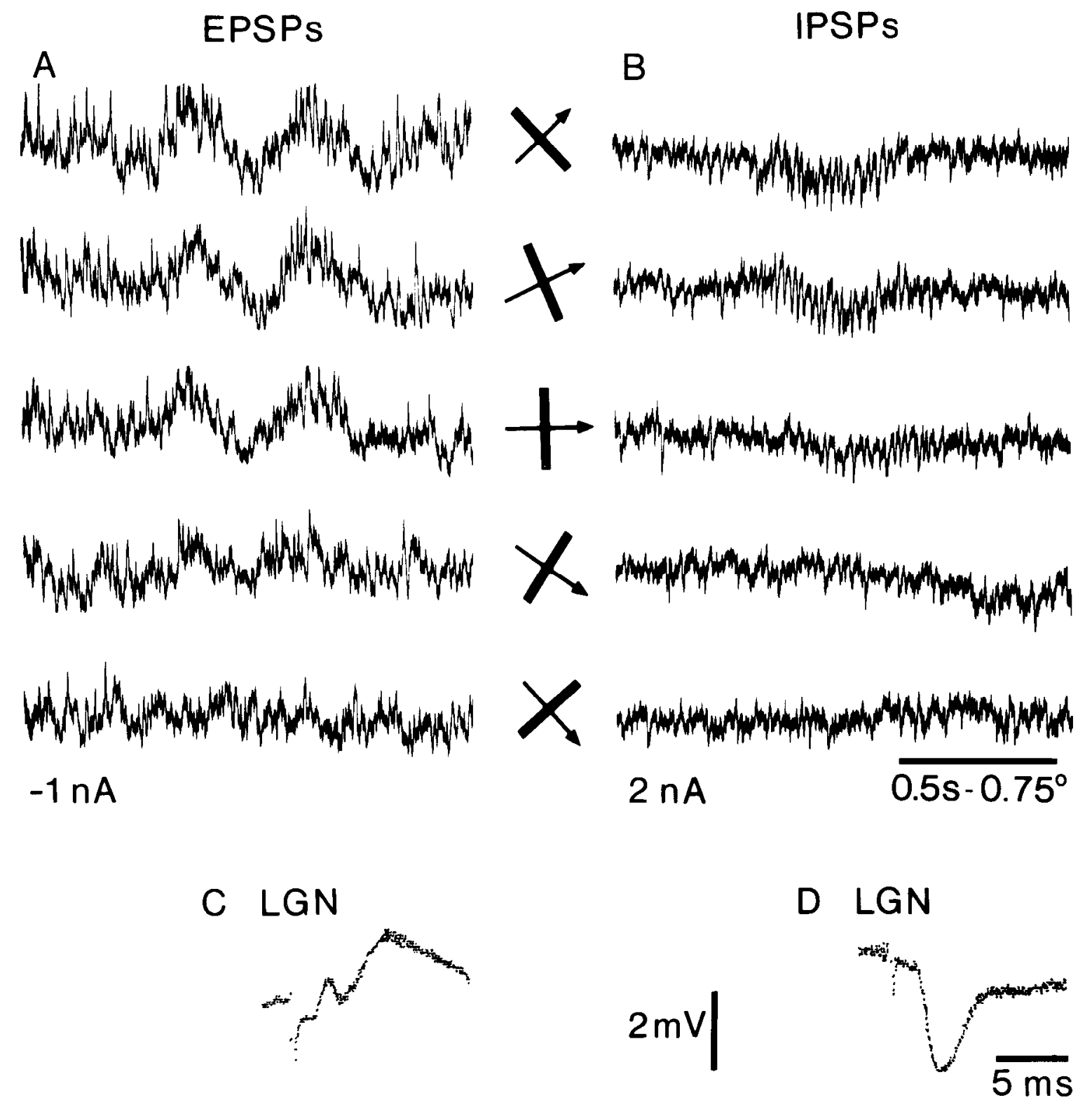

Figure 4. Comparison of the orientation selectivity of EPSPs $(A)$ and IPSPs $(B)$ in the simple cell of Figure 1. Each diagram in the center of the figure indicates the orientation and direction of motion of the stimulus used to evoke the responses to the left and right. $C$, Responses to electrical stimulation ( $1 \mathrm{~mA})$ in the LGN with the same level of current injection as in $A(-1 \mathrm{nA})$. Mono- and trisynaptic EPSPs are visible. $D$, Responses to electrical stimulation $(1 \mathrm{~mA})$ with the same level of current injection as in $B(2 \mathrm{nA})$. A disynaptic IPSP is visible. The records in both $C$ and $D$ are averages of 10 individual traces.

ulation in the LGN (Fig. 6B). Note also the presence of partially blocked action potentials in the upper records of Figure 5 . These can be seen at a higher sweep speed in Figure $6 \mathrm{~A}$. The monosynaptic EPSP evoked from the LGN (Fig. $6 B$ ) is also followed by an action potential of about the same amplitude.

As in the previous simple cell, the IPSPs again were tuned to the same orientation as the IPSPs (Fig. 5, bottom). The IPSP response was also slightly directional, but identical in form in the opposite direction of motion, and the response gradually disappeared as the stimulus was turned away from optimal, with approximately the same width of tuning as the EPSPs (not shown). The current injected through the electrode during the recording of these traces was $0.7 \mathrm{nA}$, which was sufficient to suppress EPSPs and make IPSPs visible (Fig. 6D).

The upper and lower records of Figure 5 complement each other in an important way. The EPSP records consist of two depolarizations, one for each $\mathrm{ON}$ region with a return to nearrest as the stimulus passes over the OFF region. The IPSP receptive field, in contrast, consists of a single hyperpolarization centered on, and largely confined to, the OFF region. There is little consistent response as the stimulus passes over the ON regions. Thus, the OFF regions of this simple cell and of the one illustrated in Figures 1-4 seem to be constructed from excitation from OFF-center cells in the LGN and from ON-type inhibition mediated by cortical interneurons. Note, however, that this inhibition seems not to be directly related to orientation selectivity in the cell: The EPSPs are well oriented independently of the presence of IPSPs, and in any case, the IPSPs disappear at the null orientation.

In this simple cell, as well as in all cortical cells so far examined, the slow hyperpolarization associated with the IPSP receptive field has superimposed on it a barrage of smaller, faster 


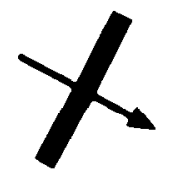

\section{EPSPs}
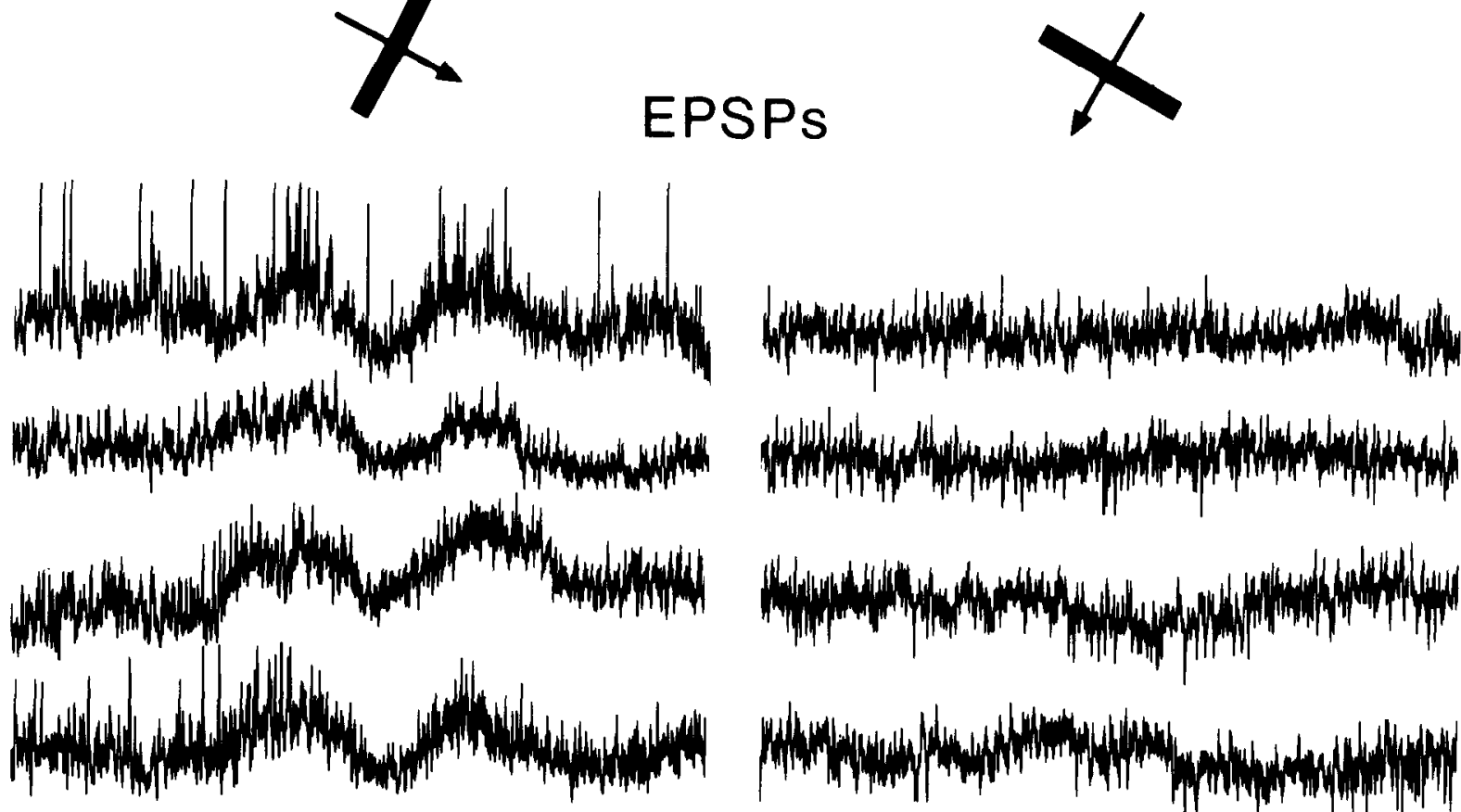

Nond
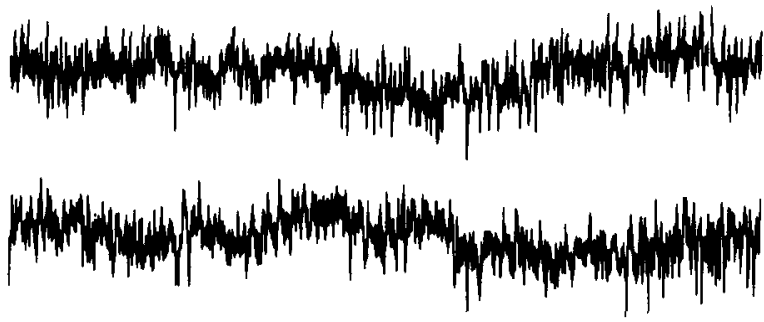

$0 \cap A$

$\boldsymbol{\Lambda}$

\section{IPSPS}

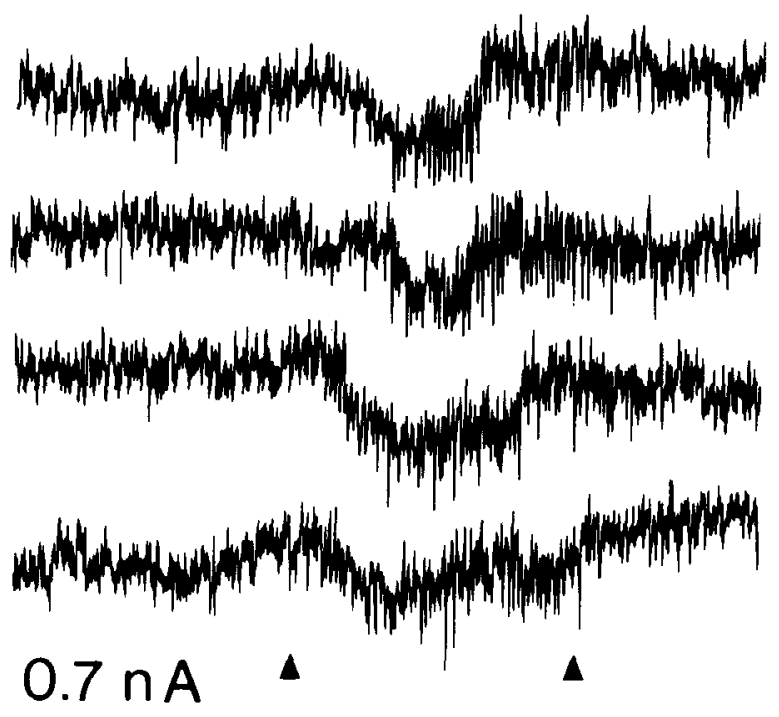

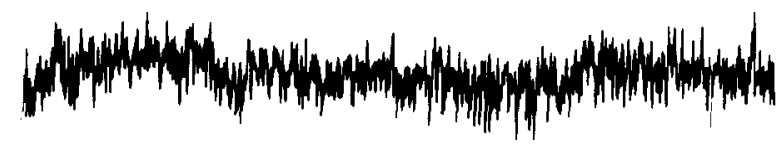
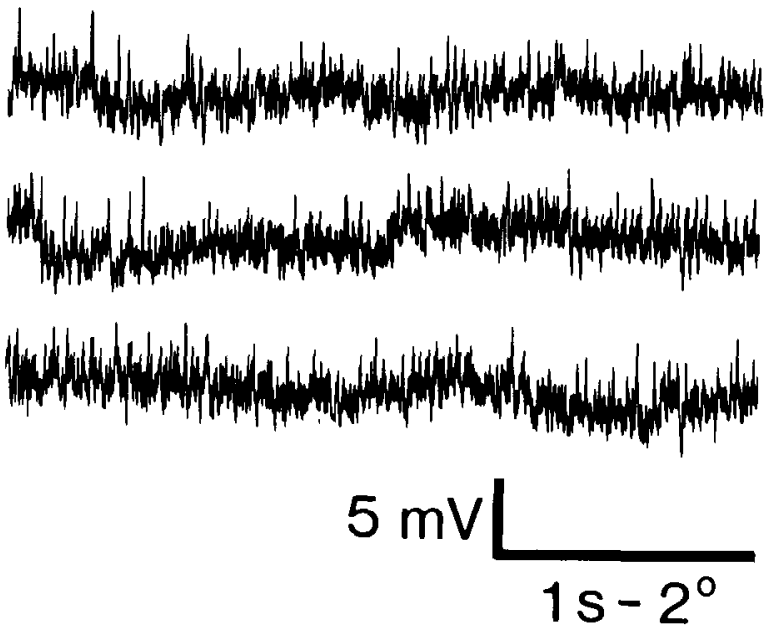

Figure 5. Visually evoked EPSPs and IPSPs from a second simple cell in layer 4. Responses to an optimally oriented bar are shown to the left, EPSPs above and IPSPs below. The responses were bidirectional, and only one direction of stimulus motion is illustrated. The portions of the first and fourth trace marked by arrows in each set are shown at higher sweep speed in Figure 6 . To the right are shown the responses to a bar oriented $90^{\circ}$ to the optimal. Again, there was no difference in the responses to the opposite direction of motion.

potentials. These may be seen at higher sweep speed in Figure $6 C$, where individual hyperpolarizing potentials of $3-5 \mathrm{mV}$ and 10-15 msec duration occur in rapid succession (approximately $50 \mathrm{~Hz}$ ) during the height of the slow depolarization. They are comparable in size and time course to the response to electrical stimulation in the LGN taken at the same level of current injection (Fig. $6 D$; note the even higher sweep speed). It is difficult to resist suggesting that the presynaptic cell or cells responsible for the visually and electrically evoked responses are one and the same.

If the source of the visually and electrically evoked synaptic potentials in layer 4 cells is identical, as suggested by their similarity, then the visual unitary events are disynaptic, presumably coming from other simple cells in layer 4 . In addition, it is likely that the type of geniculate afferent exciting a layer 4 cell and its inhibitory interneurons are identical: Ferster and 


\section{EPSPs}
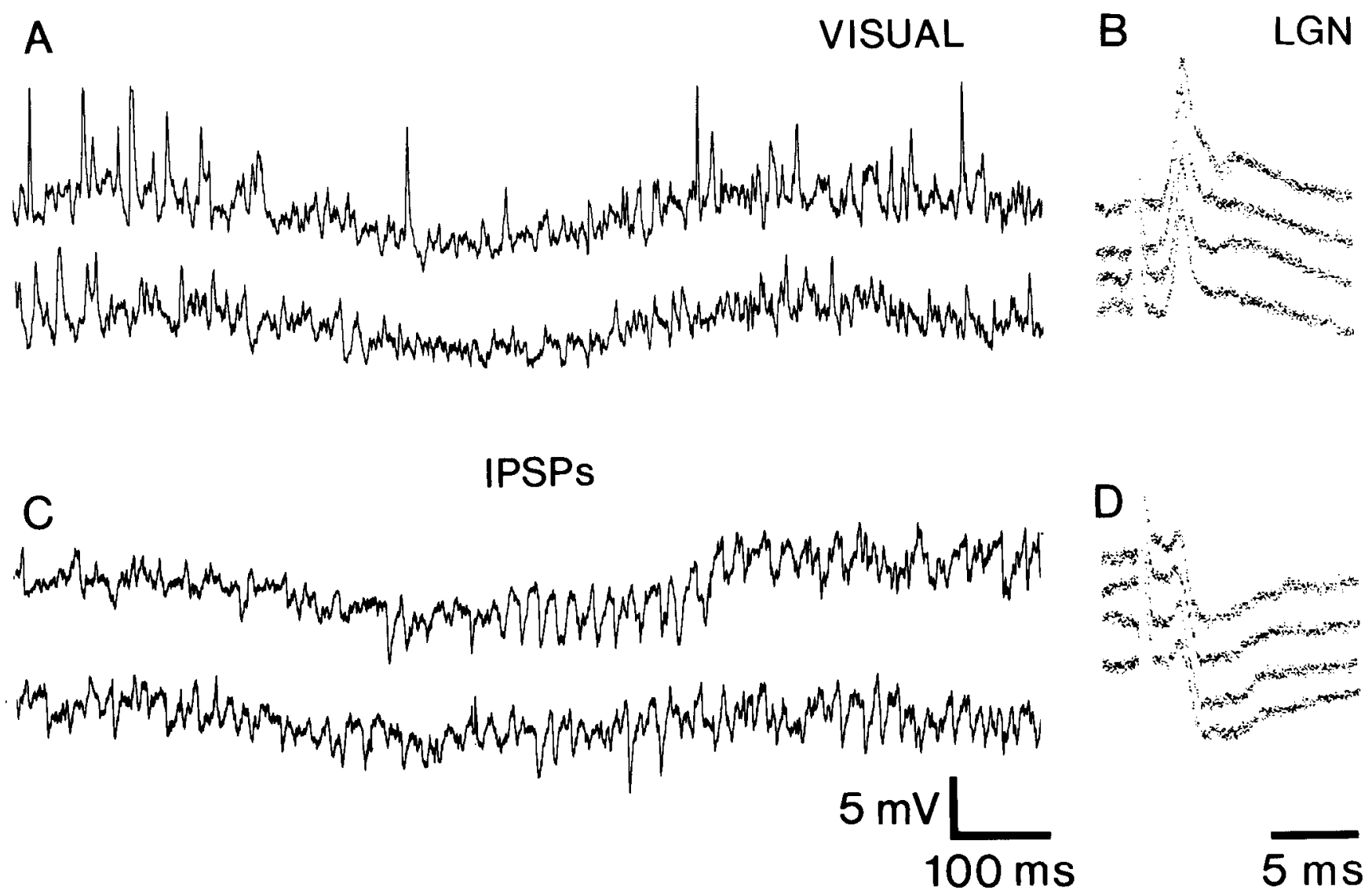

Figure 6. A, Portions of the EPSP records from Figure 5 (upper left) shown at higher sweep speed. B, Responses to electrical stimulation in the LGN taken with the same level of current injection as in $A(0 \mathrm{nA})$. Mono- and trisynaptic EPSPs are visible. $C$, Portions of the IPSP records from Figure 5 (lower left) shown at higher sweep speed. $D$, Responses to electrical stimulation in the LGN taken with the same level of current injection as in $C(0.7 \mathrm{nA})$. A disynaptic IPSP is visiblc.

Lindström (1983) found that the conduction time of fibers mediating the IPSPs and EPSPs in any given cell in layer 4 were closely related. Given that the orientation preference and receptive field position of EPSPs and IPSPs is the same, as well, it also seems that the inhibitory cell lies in the same orientation column. All of these arguments suggest that the simple cell of Figures 5 and 6 (and others like it) is powerfully inhibited by an interncuron, presumably another simple cell, whose soma is very close to the recorded cell; certainly spine-free stellate cells with locally arborizing axons are well established in layer 4 (LeVay, 1973; Lund et al., 1979).

\section{Receptive field properties of synaptic potentials in complex cells}

The orientation selectivity of synaptic potentials recorded in complex cells was no different from that of simple cells. The major difference in their responses lay in the spatial organization of the receptive fields, corresponding to the differences between extracellularly recorded receptive field organization of simple and complex cells as originally defined (Hubel and Wiesel, 1962). Figures 7-10 are taken from a complex cell in layer 2, which responded characteristically with disynaptic EPSPs and IPSPs after electrical stimulation in the LGN (Fig. 10, $C$ and $D$ ).

The $-2 \mathrm{nA}$ of current injected through the recording electrode was sufficient to suppress IPSPs and enhance EPSPs in this cell. In addition, at this level of polarization, small action potentials $(10-20 \mathrm{mV})$ of short duration were present, visible in responses both to electrical (Fig. 10C) and visual stimulation (Fig. 7A). Sweeping a slit across the receptive field in the optimal orientation reliably produced a single wave of depolarization lasting well over a second at the speed of stimulus motion used $(1 \%$ sec). The exact extent of the EPSP receptive field, however, is difficult to determine given the slow rise of the depolarization and a slight drift in the baseline of the records. It may be as large as $2^{\circ}$, but the largest increase in the noise and the largest fraction of the total depolarization occur in the central $1^{\circ}$ of the field. The action potentials visible probably do not give a reliable estimate of the receptive field that would be plotted extracellularly, given that threshold is clearly dependent on the amount of current injected into the cell at the time.

The EPSP responses are somewhat directional; sweeping the slit in the opposite direction (Fig. $7 B$ ) gives a smaller response in comparison, and as always, turning the slit $90^{\circ}$ abolishes the response altogether. In this case, where the shortest latency EPSP evoked from the LGN is disynaptic, there is no doubt that the visually evoked EPSPs are cortical in origin. At least some of the neurons of origin are likely to be simple cells located in layer 4 , which are themselves activated monosynaptically (Ferster and Lindström, 1985b; Gilbert and Wiesel, 1983). From the orientation specificity of the EPSPs it is clear that the presynaptic cells are confined to a single set of orientation columns, the one that contains the recorded cell itself.

Figure 8 contains the EPSP responses to flashing an optimally oriented stimulus in three different locations within the recep- 


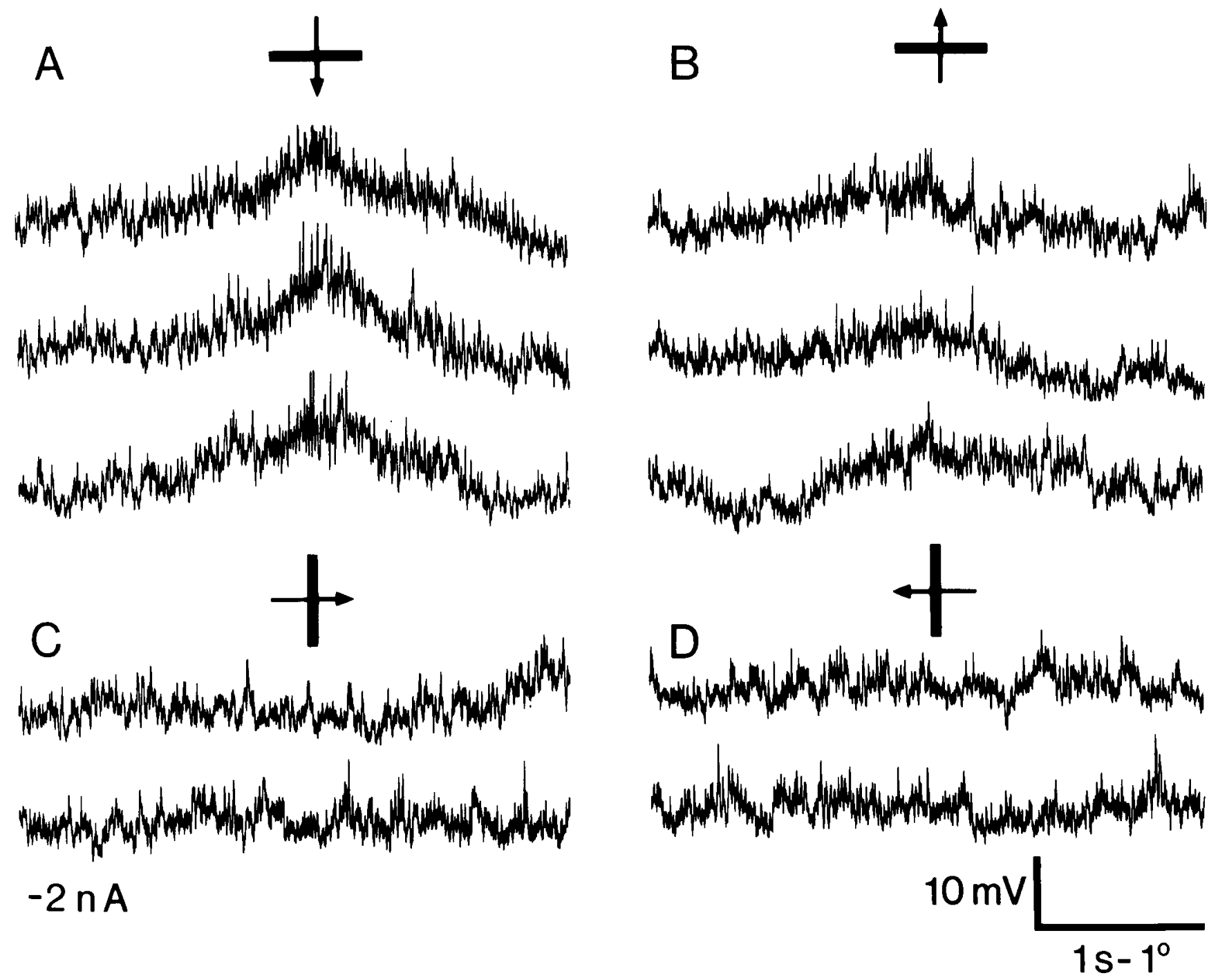

Figure 7. EPSPs recorded from a layer 2 complex cell in response to a bar of light swept across the receptive field. Conventions are the same as in Figure 1; the diagrams above each set of traces indicate the orientation and direction of motion of the stimulus. $A$ and $B$, Preferred orientation; $C$ and $D$, null orientation. The cell is hyperpolarized as indicated to suppress IPSPs and enhance EPSPs.

tive field. The horizontal bar below each set of records again indicates the period during which the stimulus was on. It is from these records that the EPSP responses can be classified unequivocally as complex. As demanded by the definition of complex cells (Hubel and Wiesel, 1962), the same type of response is evoked from each part of the receptive field-in this case, depolarization both at the onset and offset of the stimulus. The depolarization includes a large transient component, larger than any consistent maintained component. It should be noted that any increase in the higher frequency components of the trace associated with the depolarization is small at best. At least there are no obvious unitary events similar to those observed in IPSP records. It seems likely that the number of presynaptic inputs is therefore quite large, each one contributing a small fraction of the total response.

Figure 9 contains the IPSPs evoked by the same moving stimuli used to generate the records of Figure 7 , obtained with the cell depolarized by $0.6 \mathrm{nA}$ of injected current. (An average of 10 records of the response to electrical stimulation of the LGN recorded with this current is illustrated in Figure $10 D$. The earliest component visible is a disynaptic IPSP.) The IPSP receptive field is wider than the EPSP field, up to twice as wide, depending on how the two are defined. Though not tested extracellularly, there is little doubt that the parts of the IPSP receptive field extending beyond the central EPSP field would have formed inhibitory side-bands of the type described by Bishop et al. (1971). From this and other cells, it would seem that the inhibitory region extends through the entire receptive field in much the same way that the surround of a retinal ganglion cell extends through its receptive field. In the side-bands, the inhibition dominates and is clearly visible in extracellular conditioning experiments of the type introduced by Bishop et al. (1972). In the center of the receptive field, the excitatory input dominates, the net effect producing the classical excitatory part of the extracellularly defined receptive field.

The IPSPs are also direction-selective, the preferred direction being the same as that for the EPSPs, but with a smaller difference in response between the preferred and nonpreferred direction. Once again, the orientation preference of the IPSPs is identical to that of the EPSPs. As illustrated in the lower records of Figure 9 , a stimulus oriented $90^{\circ}$ to the optimal evokes no visible IPSP response. In Figure 10, it can be seen that just a $45^{\circ}$ rotation of the bar away from the optimal almost completely abolishes both the EPSP and IPSP responses. Though the IPSPS 

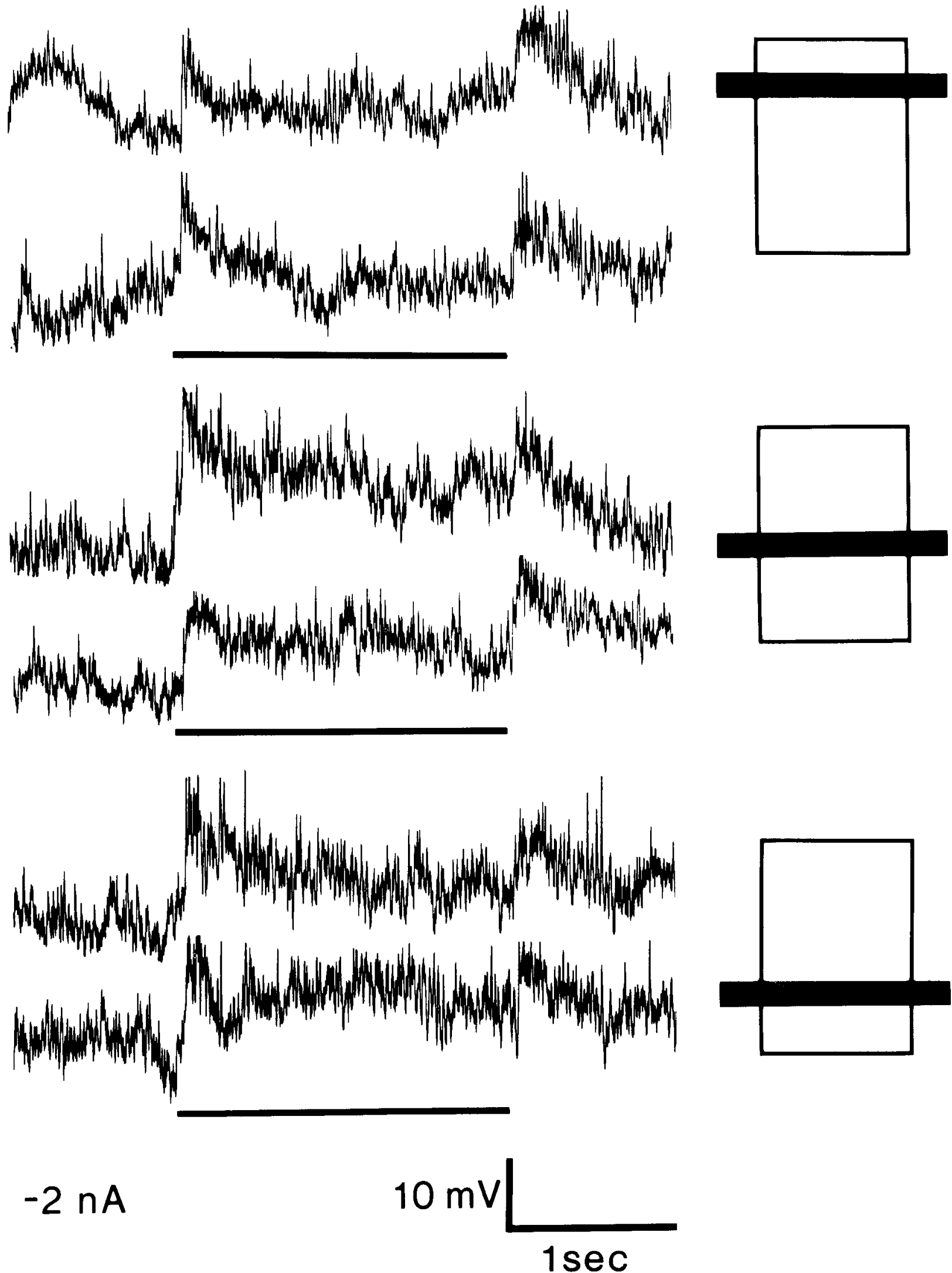

Figure 8. EPSPs recorded from the same complex cell as in Figure 7. The stimulus is a bar of light flashed in the portion of the receptive field indicated in the diagram to the right of each pair of records. The horizontal line below each pair indicates the time during which the bar was on. 

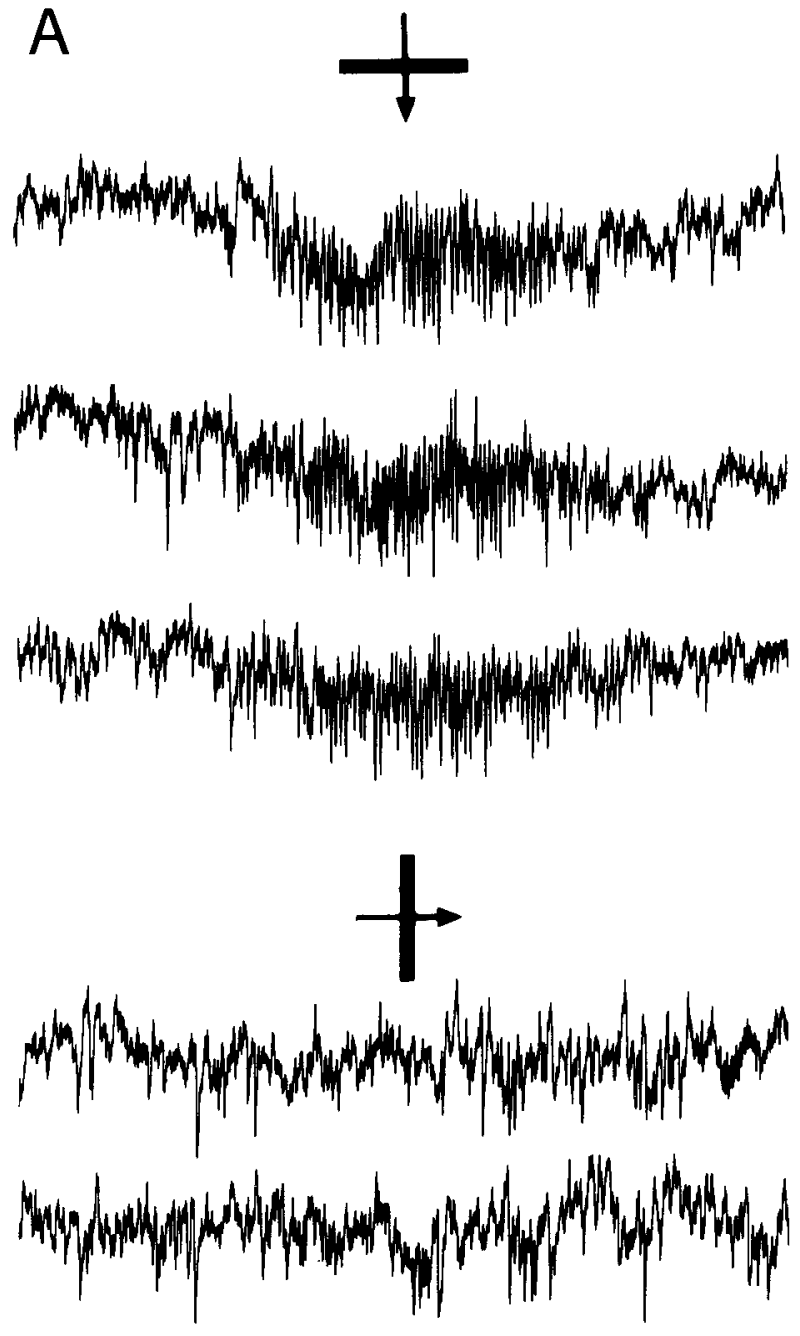

$0.6 \mathrm{nA}$
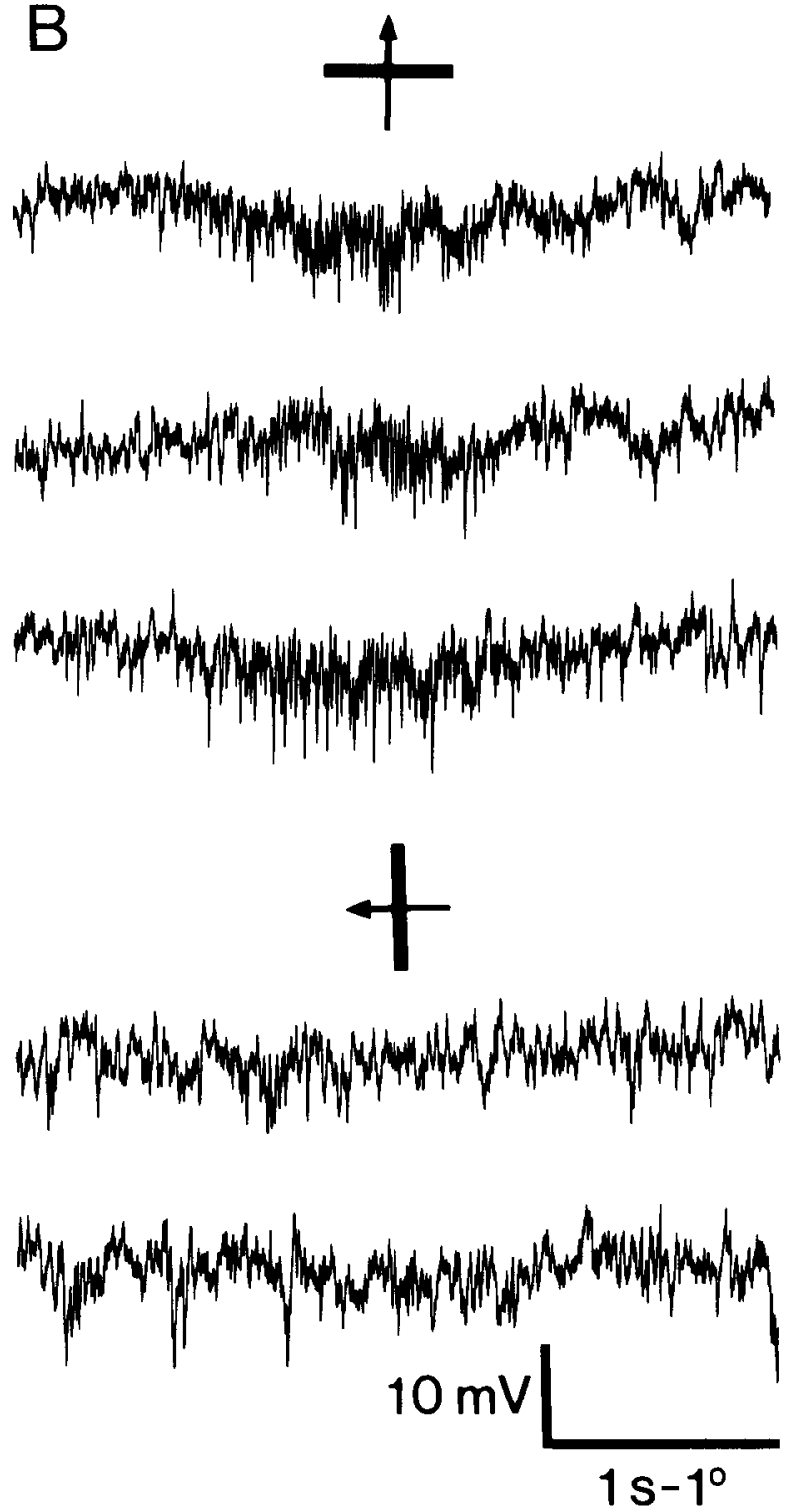

Figure 9. IPSPs recorded from the same complex cell as in Figure 7. The stimulus size, orientation, and speed are the same as for the corresponding records in Figure 7. The cell is now depolarized to suppress EPSPs and enhance IPSPs.

might have a slightly wider orientation tuning curve than the EPSPs, the two types of potential are comparable in their selectivity.

As is usual in cortical cells, the hyperpolarization evoked by the moving stimulus is associated with a vigorous burst of unitary IPSPs, seen as a series of small downward spikes in Figure 9. The maximum frequency of the burst is about $50 / \mathrm{sec}$. The bursts are shown at higher gain and sweep speed in Figure 11 , along with four individual records of the response to electrical stimulation. As in the simple cells of Figures 1-6, the number of presynaptic inhibitory neurons responsible for the bursts must be small since the maximum size of the electrical response is not much larger than the size of the unitary events. There must be more than one presynaptic neuron, however. Evidence comes from both the electrically and visually evoked responses. In Figure $11 B$, several individual traces in response to geniculate stimulation are shown. The IPSPs begin at a latency of 2.1-2.3 msec, clearly a disynaptic input. But the time course of the response is not smooth. At 3.0-3.5 msec after the stimulus artifact, a distinct second component is visible, which could either be trisynaptic or longer. From these records it seems likely that there are at least two separate inhibitory inputs to the cell. In contrast, the IPSPs evoked electrically in the simple cell of Figure 6 had a smooth time course, as if all the components were disynaptic in latency.

The visually evoked records indicate multiple inputs by their irregularity. The size of the individual events varies by over a factor of three, and they occur at irregular intervals. There must be at least two presynaptic cells producing the IPSPs of Figure 11 , one disynaptic and one trisynaptic, the former producing a larger IPSP than the latter. The largest of the events seen in the visual records arc most likcly the result of simultaneous spikes in these two cells. These large events are in fact relatively infrequent compared to the smaller ones, and they correspond in size to the electrical response, as would be expected. Many of them have an inflected shape as well, as if they were made up of two smaller events, much like the electrically croked response. Finally, the top two records in Figure $9 A$ and the top 


\section{EPSPS}
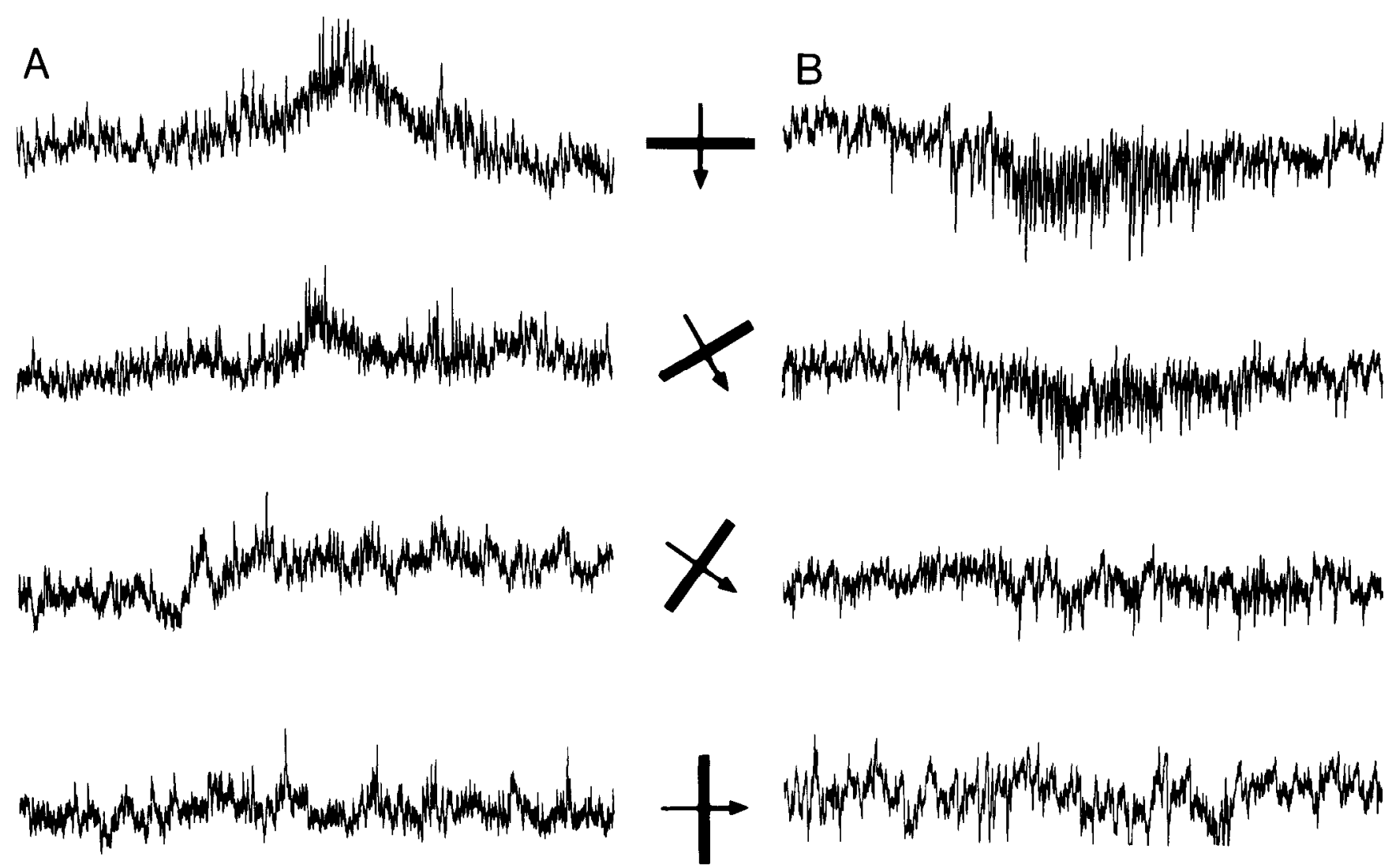

$-2 n A$
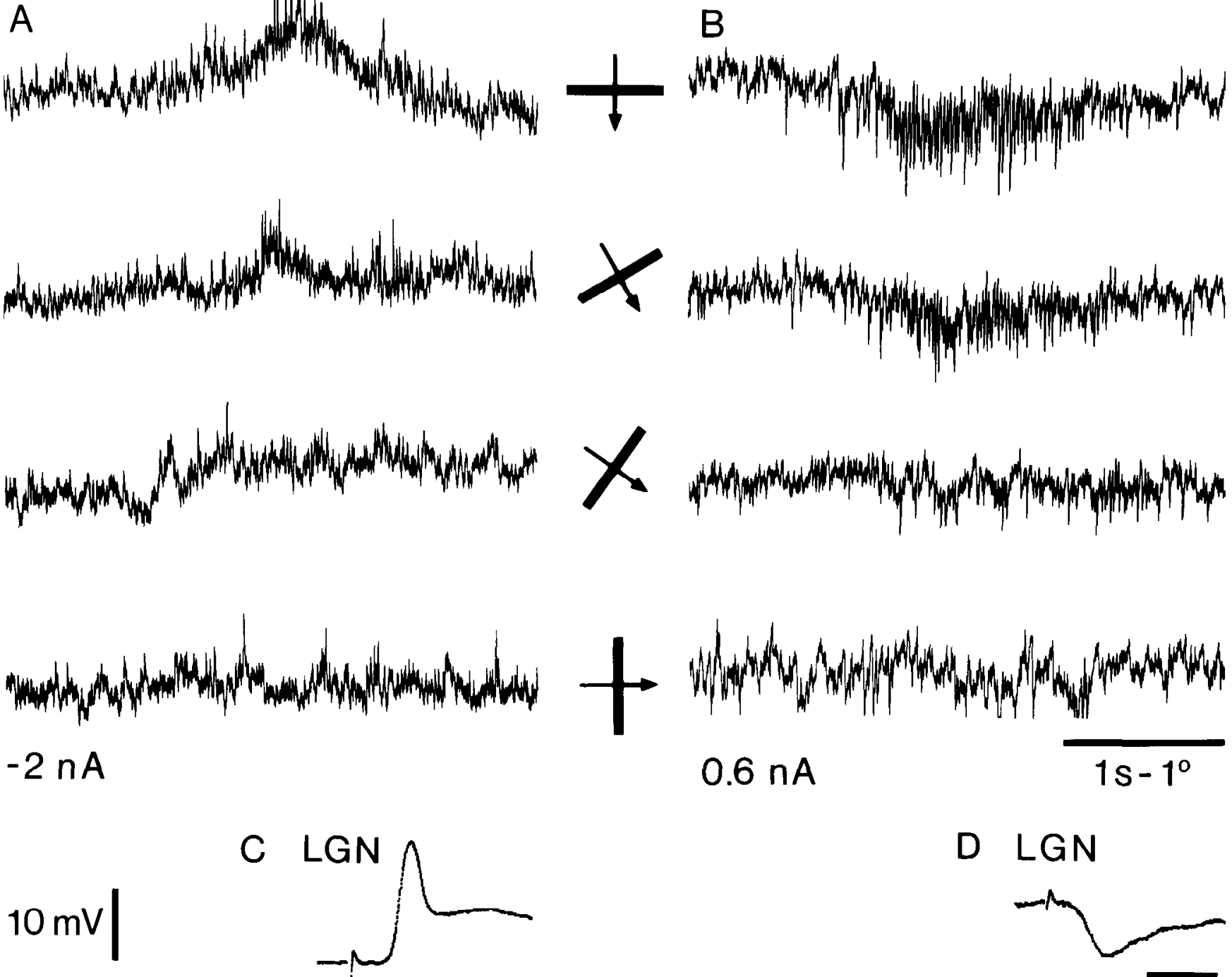

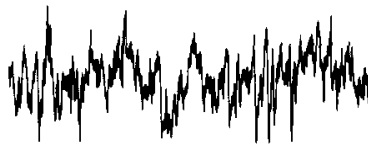

$0.6 \mathrm{nA}$
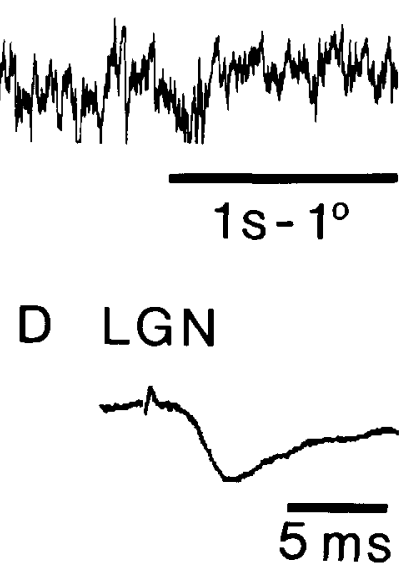

Figure 10. EPSPs $(A)$ and IPSPs $(B)$ from the same complex cell as in Figure 7 evoked by moving stimuli of different orientation to show their orientation tuning. The diagram in the center shows the stimulus orientation used to evoke the records to the left and right. $C$, The response to electrical stimulation in the LGN (1 mA), taken with the same level of current injection as $A$, includes a disynaptic EPSP. $D$, With the current injection level the same as in $B$, a disynaptic IPSP is revealed. The records in both $C$ and $D$ consist of averages of 10 individual traces.

record in Figure 10A have a biphasic time course. It is possible that the two peaks in the visually evoked inhibition correspond to the rcceptive ficlds of the two presynaptic cells. The large unitary events that seem to be the result of simultaneous spikes in the two cells occur near the center of the IPSP receptive field, where the receptive fields of the two presynaptic cells would overlap. This organization, two to three large visually evoked IPSP inputs and two separate components in the electrical response, has been observed in nine supragranular cells studied.

The orientation selectivity of potentials recorded in complex cells from other layers of the cortex was no different from that observed in cells of layer 2 . Layer 5 cells receive much of their excitatory input from corticocortical cells of the supragranular layers (Ferster and Lindström, 1983; Gilbert and Wiesel, 1983). This projection is clearly organized in a columnar fashion: The EPSPs in all six of the layer 5 cells studied were well oriented. An example is illustrated in Figure 12.
These records are different in one important respect from those of the layer 2 cell in Figures 7 and 9. Each trace contains 10 or more distinct peaks of depolarization lasting $25-50 \mathrm{msec}$ and reaching up to $10 \mathrm{mV}$ in amplitude. These appear not to be individual EPSPs, produced by a single presynaptic cell; they are longer than electrically evoked potentials in layer 5 cells. Rather, each peak seems to be made up of a small burst of unitary events, roughly $1-2 \mathrm{mV}$ in size, each one summing with the previous one. At higher gain and sweep speed, the individual events can be seen as inflections on both the rising and falling phases (Fig. 13). Occasional $60 \mathrm{mV}$ action potentials of approximately $1 \mathrm{msec}$ duration rise from the EPSPs, though the tops of the spikes are cut off in the records at the gains used. (The tallest and sharpest of the peaks in the first four traces of Figure $12 A$ and the discontinuity in Figure $13 B$ represent the base of the truncated action potentials.) The cell was also unusual in the high level of spontaneous activity in both the EPSPs 
A Visual
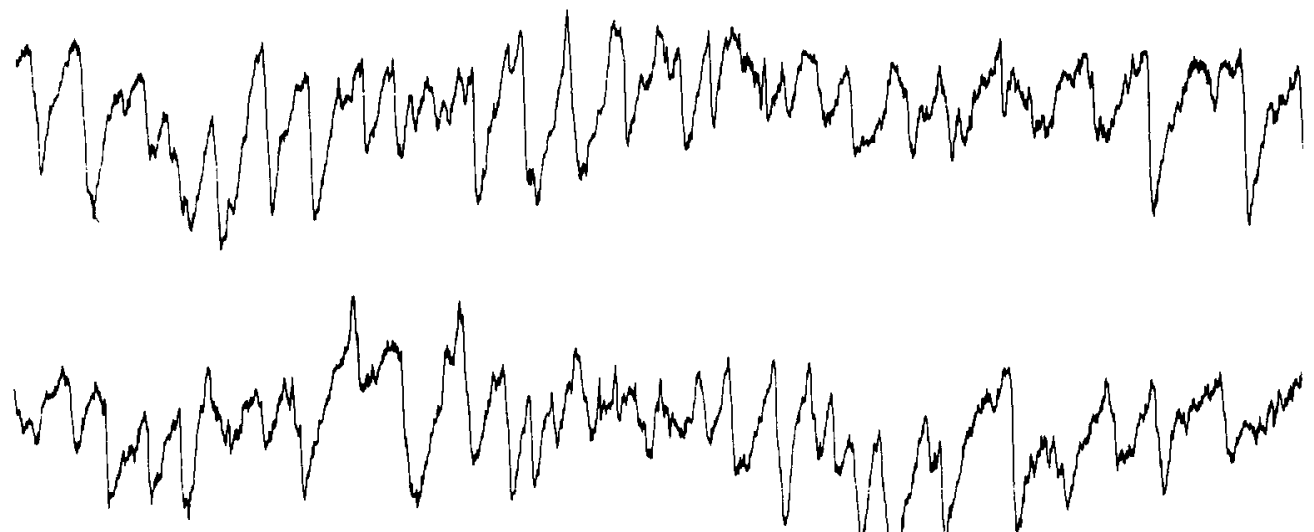

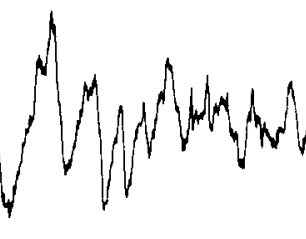

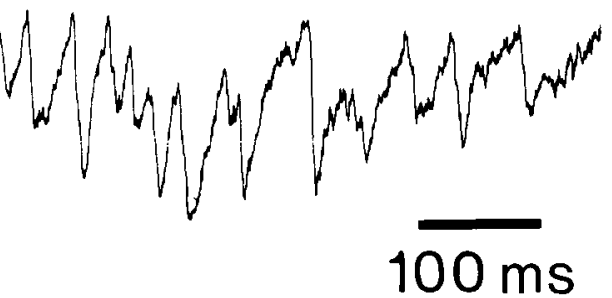

B

LGN
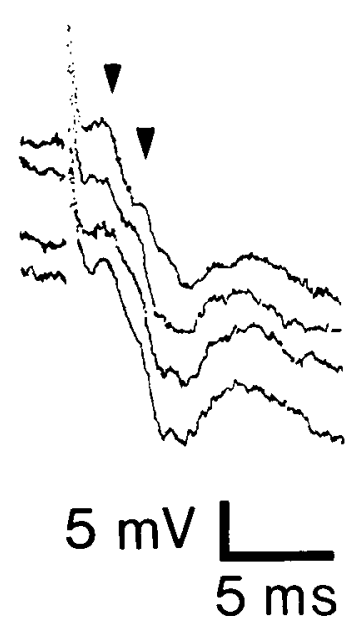

Figure 11. A, IPSPs evoked visually from the same complex cells as in Figures 7-10. At higher sweep speed, the individual hyperpolarizing potentials are clearly distinguishable. The irregular size and frequency suggest that more than one presynaptic cell is responsible for the potentials. The largest events are perhaps the result of nearly spontaneous spikes in two presynaptic cells. $B$, The response to electrical stimulation taken with the same level of current injection. At least two presynaptic cells are responsible for the electrical response. The first causes a disynaptic IPSP (first arrow), while the second causes a trisynaptic (or later) IPSP.

and IPSPs, which also arrived at the cell in bursts. The IPSP records at the preferred and null orientations are shown in Figure $12, B$ and $D$. They, too, are orientation selective with the same preferred orientation as the EPSPs. Not shown are records taken at intermediate orientations; both EPSPs and IPSPs are attenuated gradually as the orientation is changed from the optimal.

\section{Discussion}

The results presented in this paper indicate that inhibition in neurons of the visual cortex is supplied by interneurons that lie in the same set of orientation columns as the neuron itself. The same stimulus orientation evokes maximal EPSPs and maximal IPSPs. This pattern of synaptic input has now been observed in over 30 cortical neurons for which EPSPs and IPSPs could be recorded and tested at different orientations. In addition, IPSPs alone have been tested in many cells that were too depolarized by penetration to obtain EPSPs. Since penetrations were made perpendicular to the cortical surface, it was often possible to compare the IPSP orientation to that of nearby cells recorded extra- or intracellularly, which presumably were located in the same orientation column. In the over 40 cases where this comparison could be made, the orientations of the IPSPs and of nearby cells were similar.

Before accepting these results and what they imply for the construction of cortical receptive fields, one must first consider whether the records shown reflect the entire synaptic input onto recorded cells. Might some EPSPs generated in the most distal portions of the dendrites be invisible in the soma? Since the site of spike initiation is in the soma and initial segment, one would expect all EPSPs that have an effect on a cell's activity to be visible in somatic recordings. This has been tested in the hippocampus, where, because of the strict laminar segregation of excitatory afferents to the pyramidal cells, it is possible to activate separately synapses in the proximal and distal dendrites and to compare the effects seen in the cell soma. It was found that the effects of remote excitatory synapses are easily visible in the soma (Andersen et al., 1980), the length constants of pyramidal cell dendrites being comparable to their physical lengths. The experiments also indicate that the hyperpolarizing current used to enhance EPSPs has almost equal effect on proximal and distal excitatory synapses.
Nevertheless, electrical properties of neocortical cells may not be similar to those of the hippocampus. Nor are the excitatory inputs to cortical cells arranged so that the effects of distal synapses can be examined selectively as they are in the hippocampus. One input to cortical cells, however, has been localized to a portion of the dendritic tree. McGuire et al. (1984) have reconstructed the intracortical axon collaterals of HRP-injected layer 6 cells projecting to layer 4 . These terminals end preferentially on the shafts of distal dendrites of layer 4 stellate cells. The layer 6 cells involved in this projection are corticogeniculate cells, and their synaptic effect is easily identifiable in layer 4 cells after antidromic activation from the LGN (Ferster and Lindström, 1985b). In Figures $4 C$ and $6 C$, for example, layer 6 input is visible as a late, slow depolarization with a latency of 3-3.5 msec. The early, monosynaptic excitation from the LGN has been shown to originate from synapses formed predominately on dendritic spines distributed throughout the dendritic tree (Garey and Powell, 1971; LeVay and Gilbert, 1976; McGuire et al., 1984; Winfield and Powell, 1983). Since both the geniculate and layer 6 potentials can be completely suppressed by depolarizing current, in layer 4 at least, there is good evidence that it is possible to record synaptic events from pcripheral portions of the dendritic tree and to influence their size with injected current.

Another potential problem in interpreting the results presented here is that IPSPs generated in the distal dendrites might be invisible from the soma, yet profoundly affect the behavior of the cell. IPSPs, unlike EPSPs, need not produce a visible hyperpolarization in the soma to be effective. Clearly, a visible hyperpolarization will move the membrane away from threshold, making it harder for EPSPs to fire the cell. But IPSPs may also operate by shunting excitatory currents directly (Fatt and Katz, 1953). If the reversal potential for the IPSP is close to rest, then an EPSP generated at the same site or more distally would be attenuated even though the IPSP alone would produce no change in membrane potential. Shunting conductances may be detected close to the cell soma by polarizing the membrane away from the synaptic reversal potential. But if the synapses are located far enough away from the soma to be inaccessible to current, they might go undetected.

Remote shunting inhibition, if it existed, could have impor- 


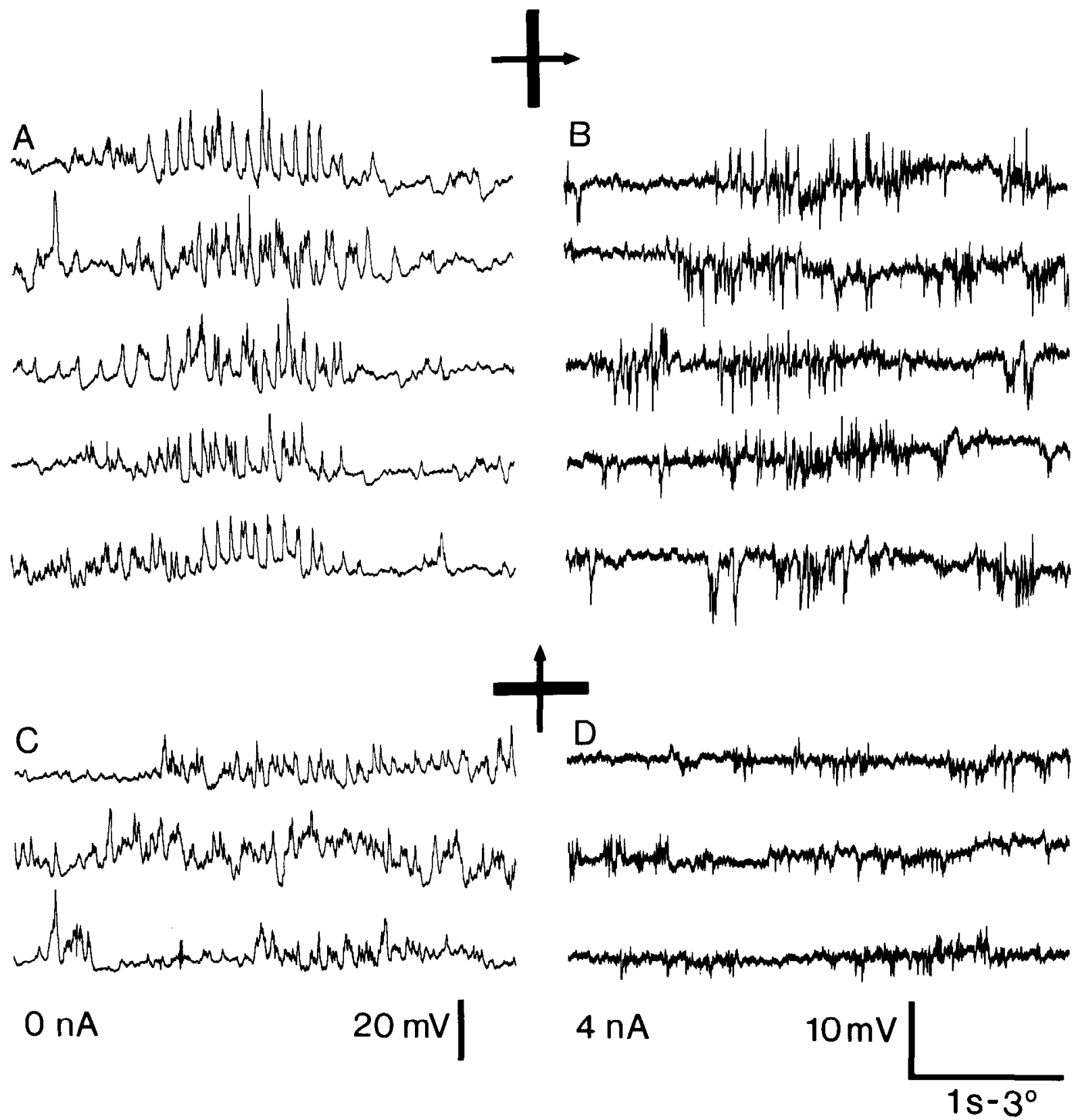

Figure 12. EPSPs and IPSPs evoked in a layer 5 complex cell by a bar of light swept across the receptive field at the optimal $(A, B)$ and null $(C$, $D$ ) orientations. $A$ and $C$, With no current being injected from the recording electrode, the visible response is made up primarily of EPSPs. $B$ and $D$, Injected current of 4 nA reveals IPSPs.

tant consequences for the results presented here. It could create the illusion of orientation tuning in EPSPs like that observed here, even if the excitatory input were not tuned at all. In other words, invisible IPSPs tuned to the null orientation, as proposed in the cross-orientation inhibition model, could attenuate all the inappropriatcly tuned EPSPs, leaving only the optimally tuned EPSPs to be visible in the cell body. The results of the current injection experiment provide strong evidence against this possibility. As shown by Koch and Poggio (1985), shunting IPSPs must be generated proximal to the EPSPs if they are to have an effect on EPSP amplitudes at the soma. But since the orientationtuned EPSPs can be suppressed by injected current, any IPSP generated proximal to the EPSPs must also be accessible to current. A shunting conductance tuned to the null orientation would be invisible only at its reversal potential. Because all responses to stimuli at the null orientation were examined at two or more levels of polarization, such IPSPs should have been visible at one level at least. It therefore seems likely that the observed orientation tuning of EPSPs arises from the organization of their sources, not by an interaction with IPSPs within the postsynaptic cell.

\section{Comparison with previous experiments}

The first evidence for cross-orientation inhibition came from extracellular experiments with two visual stimuli, one of them a conditioning stimulus. Most cortical cclls arc silent in the absence of a visual stimulus, having little spontaneous activity. As a result, inhibitory influences on them are hard to detect extracellularly; visually evoked inhibition may make a cell even less inclined to fire than it would be in the absence of the stim- 

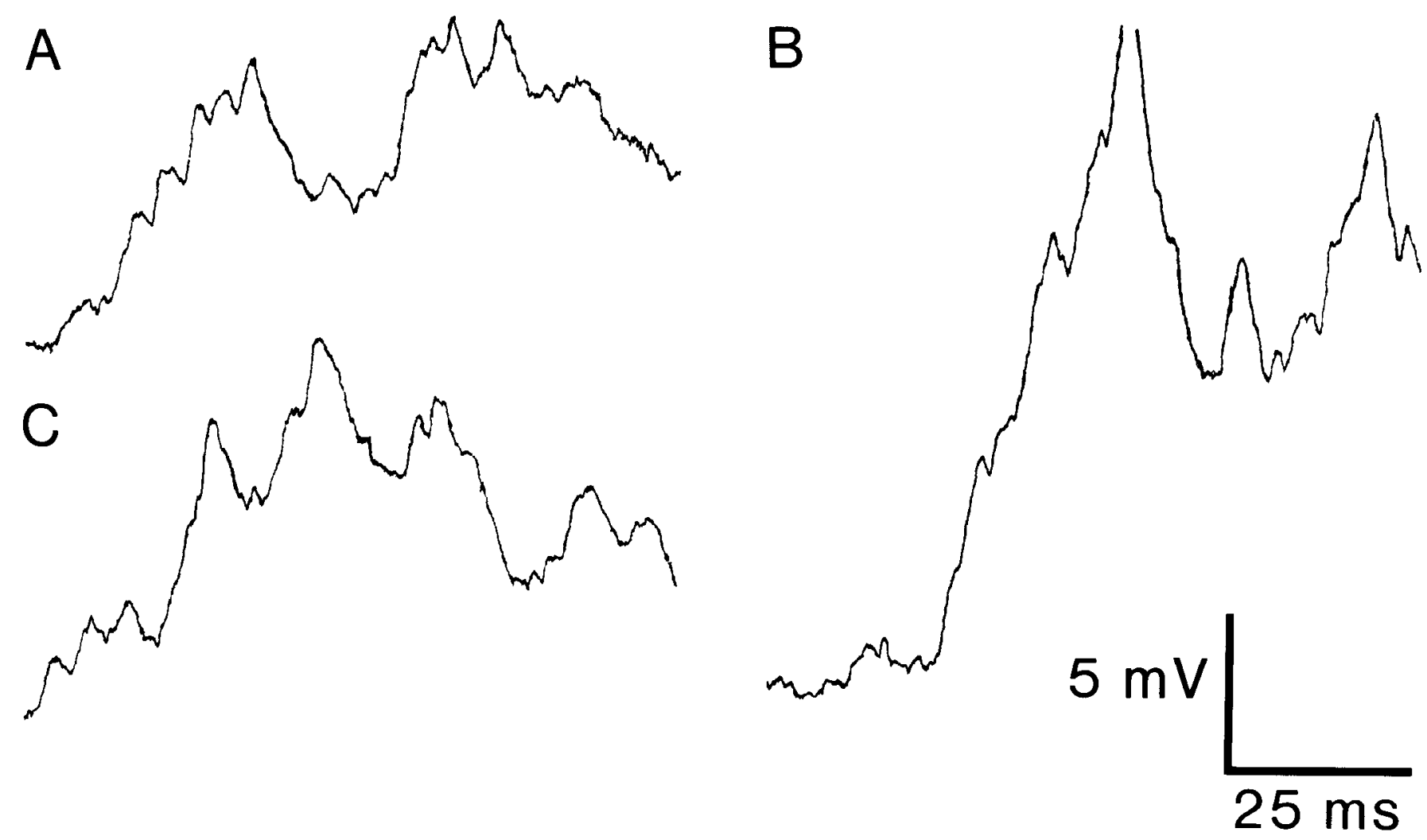

Figure 13. EPSPs evoked from the samc laycr 5 cell as in Figure 12 by an optimally oriented bar. At the higher gain and sweep speed used here, the individual EPSP components that make up the peaks of depolarization in Figure $12 A$ are visible. The base of a $60 \mathrm{mV}$ spike is present in $C$ at the discontinuity in the trace.

ulus, but the result is still no spikes. To get around this problem, Bishop et al. (1971) presented two visual stimuli at once. A conditioning stimulus was used to create background activity, and the effect of a test stimulus on this activity defined the excitatory and inhibitory regions of the receptive field. The technique has been used to show that a test stimulus at $90^{\circ}$ from the optimal orientation of a receptive field suppresses many cortical cells (Bishop et al., 1971; Morrone et al., 1982). All these authors take their results as evidence for cross-orientation inhibition.

Both of these experiments were performed with the test and conditioning stimuli presented to the same eye. As a result, the stimuli interact not only at the level of the cortex, but in the LGN as well. The combined result of two stimuli may producc a smaller excitatory drive to geniculate neurons than the conditioning stimulus alone. For example, with the two stimuli moving through the visual field independently, the test stimulus will invariably fall on the surround of a cell that would otherwise respond vigorously to the conditioning stimulus. Particularly if the stimuli have high contrast and evoke near-saturating responses, the net effect of the test stimulus will be to reduce the total geniculate drive to the cortex. It could be the resulting reduction in the activity of cortical cells by the test stimulus that has been mistaken for orientation-specific inhibition by most authors, when the true source is a reduction in excitation. The results of recent experiments, in which two orthogonal stimuli have been applied to the receptive fields of geniculate neurons, bear this out.

Several groups have obtained results from two-stimulus experiments more compatible with the intracellular records presented here. Blakemore and Tobin (1972), Nelson and Frost (1978), and Fries et al. (1977) found suppression tuned to the same orientation as the excitatory receptive field in at least some of the cells they studied. The main difference between their studies and those cited above was that the conditioning stimulus was confined to the classical excitatory receptive field, while the test stimulus was presented only in the surround. When the two stimuli were never given a chance to overlap, cross-orientation inhibition was not observed.

Binocular two-slit experiments also fail to reveal cross-orientation inhibition. A test stimulus oriented $90^{\circ}$ from the optimal has very little effect on the background activity evoked by a conditioning stimulus if it is presented to the opposite eye as the conditioning stimulus (Ferster, 1981). This experiment could be interpreted in one of two ways: (1) synaptic inputs from the two eyes do not interact, that is, inhibition from one eye does not block the excitation evoked from the other; or (2) there is, in fact, little inhibition evoked by an improperly oriented stimulus. The first possibility is clearly untrue: When both stimuli are properly oriented, powerful inhibition from one eye can completely suppress the response to an excitatory input from the other eye. Such an interocular interaction is required for the dramatic sensitivity to retinal disparity seen both in cat and monkey (see Poggio and Poggio, 1984, for review). Thus, when two stimuli are presented to different eyes or to different parts of the visual field in the same eye, cross-orientation inhibition is not observed. Only when two stimuli fall simultaneously onto the receptive fields of the same geniculate neurons is crossorientation inhibition present, making it more likely that the effect depends on interference between the excitatory signals generated in the retina or LGN.

It should be noted here that a number of psychophysical experiments in which the apparent orientation of one stimulus can be changed by the presence of another close by may also have been misinterpreted as evidence for cross-orientation inhibition (Carpenter and Blakemore, 1973; Tolhurst and Thomp- 


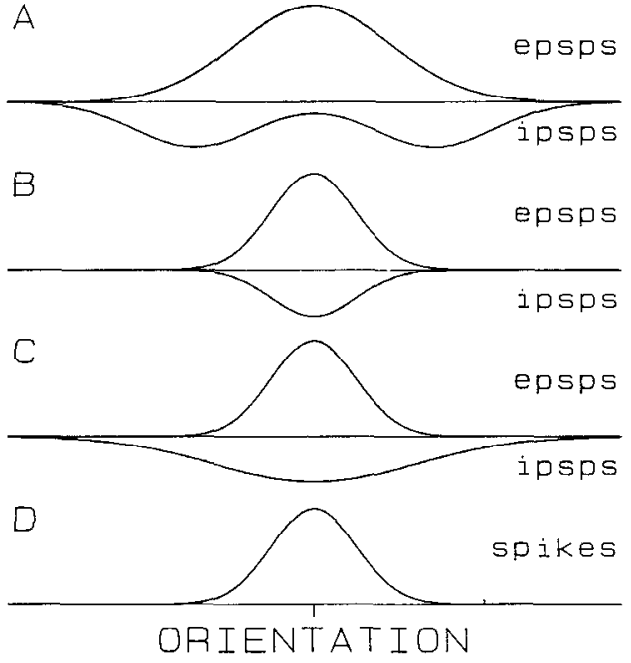

Figure 14. A-C, Maximal amplitude of visually evoked EPSPs (plotted upward) and IPSPs (plotted downward) as a function of stimulus orientation according to three different models: $A$, cross-orientation inhibition; $B$, as observed in the present experiments; EPSPs and IPSPs have similar orientation tuning and preference; $C$, EPSPs and IPSPs shown having the same orientation preference, but different tuning widths; $D$, orientation tuning of a cell as recorded extracellularly.

son, 1974). They, too, may be the result of the destructive interference between stimuli at the level of the LGN. Particularly suggestive is the observation of the later study that the effect is most pronounced when the stimuli have high contrast. Stimuli of more moderate contrast would perhaps interact more linearly.

A third line of argument in favor of cross-orientation inhibition comes from experiments with GABA antagonists. When these drugs are applied iontophoretically in the cortex, cells recorded in the vicinity lose their orientation selectivity (Sillito, 1979; Sillito et al., 1980; Tsumoto et al., 1980). The conclusion has been drawn that the drugs prevent the inhibition necessary to suppress the response to excitation at the improper orientations. But GABA antagonists have effects other than the removal of orientation-specific inhibition. They must also cause a tonic depolarization of cortical cells, a fact evident from the increase in spontaneous activity present in many published records of cells to which GABA antagonists have been applied; the cells are clearly closer to threshold. This nonspecific depolarization could in fact be responsible for the loss of orientation selectivity. With all the cells in an area several hundred microns wide in a hyperexcitable state as a result of a nonspecific removal of inhibition by the drug, the smallest excitation evoked by an inappropriately oriented stimulus, which under normal circumstances would be far below threshold, could become very effective, particularly if excitatory connections between affected cells were to reinforce the effect.

Control experiments with depolarizing agents such as glutamate do not apparently affect orientation, though whether application of tonic depolarization can be compared to the withdrawal of a series of transient IPSPs is not clear. If, in fact, GABA-mediated inhibition does play an important role in orientation selectivity, the present experiments would suggest that it is not in the form of cross-orientation inhibition.

One final possibility that should be mentioned is that the IPSPs appropriate to cxplain the effects of bicuculline might not be seen intracellularly because they are mediated by presynaptic inhibition. This is unlikely since the GABA receptor responsible for presynaptic inhibition $\left(\mathrm{GABA}_{\mathrm{B}}\right.$ receptor) is not thought to be sensitive to bicuculline or its analogs (Bowery et al., 1980).
Orientation selectivity of synaptic potentials

The cross-orientation model is represented in Figure 14 $A$, where the magnitude of visually evoked EPSPs and IPSPs is plotted as a function of stimulus orientation. Increasing excitation is plotted upward, increasing inhibition, downward. According to the model, the width of tuning of the EPSPs is broader than the response of the cell measured extracellularly, which is indicated in Figure 14D. The IPSPs are responsible for preventing the cell from responding to the EPSPs present at the edge of the EPSP tuning curve.

Figure $14 B$ represents the organization of visual inputs to cortical cells as observed in Results. EPSPs and IPSPs have exactly the same orientation preference and approximately the same width of orientation tuning. At the very least, the amplitude of both types of potential decreases smoothly as the stimulus is rotated away from the optimal. The tuning width of the receptive field measured extracellularly is likely to differ little from that measured intracellularly, except perhaps for the effect of threshold on the smallest EPSPs near the edges of the tuning curve. While the net excitation to both simple and complex cells are both well tuned, it is worth stressing that the way in which the effect is achieved in the two types of cell is quite different. In complex cells, each individual synaptic input is well tuned, coming as it does from another cortical cell in the same orientation column.

In contrast, the individual synaptic inputs to cortical simple cells coming from geniculate principal cells are not orientationselective at all; it is only their summed effect that is tuned. The simplest explanation for the orientation selectivity of the EPSPs is that proposed by Hubel and Wiesel; namely, it results from the spatial organization of the receptive fields of the presynaptic geniculate neurons. That is, a stimulus hitting the receptive field from the side would cover only a part of the ON subfields since they are elongated parallel to the cell's orientation axis. Furthermore, the bar would simultaneously stimulate the OFF region; the resulting withdrawal of excitation by the OFF-center cells would in part cancel the already weak contribution from the ON-center cells. In support of this hypothesis is the observation that the orientation selectivity of most simple cells can be predicted quantitatively from the spatial arrangement of their subfields, making only the assumption of linear spatial summation within the receptive field (Jones and Palmer, 1984).

Confounding this simple view, however, are the results of Schiller (1982) and of Sherk and Horton (1984). They found that in both monkey and cat, cortical neurons retain their orientation specificity even when activity in the ON-center retinal ganglion cells is completely blocked by intraocular injection of APB (D,L-2-amino-4-phosphonobutyric acid). Thus, the notion of the interaction between ON and OFF channels in single cortical simple cells producing orientation selectivity becomes less compelling.

In their APB study, Sherk and Horton also found evidence for ON inhibition to cortical OFF regions in that simple cells seemed to be disinhibited by the drug. In the present experiments, the inhibition produced by moving light bars was largely confined to the OFF regions of the simple cells examined (Figs. 3 and 5), supporting Sherk and Horton's interpretation. This inhibition is most likely mediated by other simple cells in the vicinity of the recorded cell (Ferster and Lindström, 1983), in particular, from cells with ON regions in the part of the visual field where the recorded cell has an OFF region. If ON regions also show hidden OFF-inhibition, then a cell recorded in the presence of APB would consist of an OFF-excitatory region and an adjacent $O F F$-inhibitory region. This organization could contribute to a cell's orientation selectivity: A null-oriented stimulus would encounter both the excitatory and inhibitory regions, which would cancel in the same way proposed for ON and OFF excitation. But the arrangement is not as simple as the original 
Hubel and Wiesel model; the inhibitory interneuron is located in the cortex and is thought to be orientation selective itself. Unless it fires at the null orientation, it would not produce the inhibition required to counteract the OFF excitation. For the interneuron to contribute to orientation selectivity in the APBtreated animals, it would have to fire at least a small amount at the null orientation, yet no effect on cortical orientation tuning of APB has been reported.

Some consideration should be given to the idea that IPSPs could be more broadly tuned than the EPSPs in orientation. While no evidence for this was found in the current experiments, the test used was less than quantitative. This possibility is represented in Figure 14C. The IPSPs in this case would still have no sharpening effect on the orientation tuning of the cell greater than a simple threshold mechanism, as suggested by Blakemore and Tobin (1972); the inhibition is maximal at the preferred orientation and decreases away from it. If IPSPs are thought to shunt the excitatory input that would otherwise reach the soma, the orientation tuning curve of the cell would, in fact, be slightly blunted. What inhibition of this sort could produce, however, is the psychophysical interactions between stimuli of similar orientation. A stimulus turned slightly away from the optimal would activate only inhibitory input to a cell. Any activity evoked by a second, optimally oriented stimulus would be reduced, presumably resulting in a distorted perception of orientation. Determining whether this mechanism actually exists requires more quantitative measures of the orientation tuning of synaptic potentials.

What then, is the role of the powerful inhibition that occurs simultaneously with excitation in response to an optimally oriented stimulus? Changes in many aspects of a stimulus other than orientation result in strong modulation of the amplitude of a cell's response, including end-stopping, side-band inhibition, retinal disparity, direction selectivity, spatial frequency selectivity, and more. It is the contribution by inhibition to the creation of these properties that will be the subject of future experiments.

\section{References}

Alger, B. E., and R. A. Nicoll (1982) Pharmacological evidence for two kinds of GABA receptor on rat hippocampal pyramidal cells studied in vitro. J. Physiol. 329: 125-141.

Andersen, P., H. Silfvenius, S. H. Sundberg, and O. Sveen (1980) A comparison of distal and proximal dendritic synapses on CA1 pyramids in guinea-pig hippocampal slices in vitro. J. Physiol. 307: 273299.

Bishop, P. O., J. S. Coombs, and G. H. Henry (1971) Interaction effects of visual contours of the discharge frequency of simple striate neurones. J. Physiol. 219: 659-687.

Blakemore, C., and E. A. Tobin (1972) Lateral inhibition between orientation detectors in the cat's visual cortex. Exp. Brain Res. 15: 439-440.

Bowery, N. G., A. Doble, D. R. Hill, A. L. Hudson, D. N. Middlemiss, J. Shaw, and M. J. Turnbull (1980) (-) Buclofer decreases neurotransmitter release in the mammalian CNS by an action at a novel GABA receptor. Nature 284: 287-303.

Carpenter, R. H. S., and C. Blakemore (1973) Interactions between orientations in human vision. Exp. Brain Res. 18: 287-303.

Creutzfeldt, O. D., U. Kuhnt, and L. A. Benevento (1974) An intracellular analysis of visual cortical neurones to moving stimuli: Responses in a cooperative neuronal network. Exp. Brain Res. 21: 251274.

Fatt, P., and B. Katz (1953) The effect of inhibitory nerve impulses on a crustacean muscle fiber. J. Physiol. 121: 374-389.

Ferster, D. (1981) A comparison of binocular depth mechanisms in areas 17 and 18 of the cat visual cortex. J. Physiol. $311: 623-655$.
Ferster, D., and S. Lindström (1983) An intracellular analysis of geniculocortical connectivity in area 17 of the cat. J. Physiol. 342: 181215.

Ferster, D., and S. Lindström (1985a) Augmenting responses evoked in area 17 of the cat by intracortical collaterals of corticogeniculate cells. J. Physiol. 367: 217-232.

Ferster, D., and S. Lindström (1985b) Synaptic excitation of neurones in area 17 of the cat by intracortical axon collaterals of corticogeniculate cells. J. Physiol. 367: 233-252.

Fries, W., K. Albus, and O. D. Creutzfeldt (1977) Effects of interacting visual patterns on single cell responses in cat's striate cortex. Vis. Res. 17: 1001-1008.

Garey, L. J., and T. P. S. Powell (1971) An experimental study of the termination of the lateral geniculo-cortical pathway in the cat and monkey. Proc. R. Soc. London [Biol.] 179: 41-63.

Gilbert, C. D., and T. N. Wiesel (1983) Clustered intrinsic connections in cat visual cortex. J. Neurosci. 5: 1116-1133.

Hubel, D. H., and T. N. Wiesel (1962) Receptive fields, binocular interaction and functional architecture in the cat's visual cortex. J. Physiol. 160: 106-154.

Innocenti, G. M., and L. Fiore (1974) Post-synaptic inhibitory components of responses to moving stimuli in area 17. Brain Res. 80 : $122-126$.

Jones, J., and L. Palmer (1984) Simple receptive fields in cat striate cortex: A comparison with Gabor functions in two dimensions of space and two dimensions of spatial frequency. Soc. Ncurosci. Abstr. 10: 800 .

Koch, C., and T. Poggio (1985) The synaptic veto mechanism: Does it underlie direction and orientation selectivity in the visual cortex. In Models of the Visual Cortex, D. Rose and V. G. Dobson, eds., Wiley, New York.

LeVay, S. (1973) Synaptic patterns in the visual cortex of the cat and monkey. Electron microscopy of Golgi preparations. J. Comp. Neurol. 150: 53-86.

Lund, J. S., G. H. Henry, C. L. Macqueen, and A. R. Harvey (1979) Anatomical organization of the primary visual cortex (area 17) of the cat. A comparison with area 17 of the monkey. J. Comp. Neurol. 184: 599-618.

McGuire, B. A., J.-P. Hornung, C. D. Gilbert, and T. N. Wiesel (1984) Patterns of synaptic input to layer 4 of the cat striate cortex. J. Neurosci. 4: 3021-3033.

Morrone, M. C., D. C. Burr, and L. Maffei (1982) Functional implications of cross-orientation inhibition of cortical visual cells. I. Neurophysiological evidence. Proc. R. Soc. London [Biol.] 216: 335-354.

Nelson, J. I., and B. J. Frost (1978) Orientation-selective inhibition from beyond the classic visual receptive field. Brain Res. 139: 359365.

Poggio, G. F., and T. Poggio (1984) The analysis of stereopsis. Annu. Rev. Neurosci. 7: 379-412.

Schiller, P. H. (1982) Central connections of the retinal ON and OFF pathways. Nature 297: 580-583.

Sherk, H., and J. C. Horton (1984) Receptive field properties in the cat's area 17 in the absence of $\mathrm{ON}$-center geniculate input. J. Neurosci. 4: 381-393.

Sillito, A. M. (1979) Inhibitory mechanisms influencing complex cell orientation selectivity and their modification at high resting discharge levels. J. Physiol. 289: 33-53.

Sillito, A. M., J. A. Kemp, J. A. Milson, and N. Berardi (1980) A reevaluation of the mechanisms underlying simple cell orientation selectivity. Brain Res. 194: 517-520.

Tolhurst, D. J., and P. G. Thompson (1975) Orientation illusions and after-effects: Inhibition between channels. Vis. Res. 15: 967-972.

Tsumoto, T., W. Eckart, and O. D. Creutzfeldt (1979) Modification of orientation sensitivity of cat visual cortex neurons by removal of GABA-mediated inhibition. Exp. Brain Res. 34: 351-363.

Winfield, D. A., and T. P. S. Powell (1983) Laminar cell counts and geniculocortical boutons in area 17 of cat and monkey. Brain Res. 277: 223-229. 